\title{
WNT signalling in prostate cancer
}

Virginia Murillo-Garzón ${ }^{1}$ and Robert Kypta ${ }^{1,2}$

${ }^{1}$ Cell Biology and Stem Cells Unit, CIC bioGUNE, Building 801A, Bizkaia Technology Park, Derio 48160, Spain

${ }^{2}$ Department of Surgery and Cancer, Imperial College London, Du Cane Road, London W12 0NN, UK

Biographies:

Robert Kypta is a Principal Investigator at CIC bioGUNE, a Centre of Excellence Severo Ochoa near Bilbao, and a Lecturer in Prostate Cancer at Imperial College London. His research interests focus on how extracellular signals control cell fate during prostate cancer progression and neuronal differentiation.

Virginia Murillo Garzón is a PhD student at CIC bioGUNE, a Centre of Excellence Severo Ochoa near Bilbao. She has BSc in Biotechnology from the University of Salamanca and a Masters in Regenerative Biomedicine from the University of Granada. Her PhD is on Wnt receptor signalling in prostate cancer. 
Abstract Genome sequencing and gene expression analyses of prostate tumours have highlighted the potential importance of genetic and epigenetic changes observed in WNT signalling pathway components in prostate tumours, particularly in the development of castration-resistant prostate cancer. WNT signalling is also important in the prostate tumour microenvironment, where WNT proteins secreted by the tumour stroma promote therapy resistance, and in prostate cancer stem or progenitor cells, where WNT- $\beta$-catenin signals promote self-renewal or expansion. Preclinical studies have demonstrated the potential of inhibitors that target WNT-receptor complexes at the membrane or that block the interaction of $\beta$-catenin with LEF1 and the androgen receptor, in preventing prostate cancer progression. Some Wnt signalling inhibitors are in Phase I trials, but they have yet to be tested in patients with prostate cancer.

Prostate cancer was the most commonly diagnosed cancer and second leading cause of cancer death in men in the USA in $2016^{1}$. Androgen deprivation therapy (ADT) is the standard of care for men with prostate cancer, owing to the essential role of the androgen receptor (AR) in the normal growth and development of the prostate gland, as well as in prostate carcinogenesis ${ }^{2,3,4}$. Unfortunately, most tumours progress to an aggressive state, known as castration-resistant prostate cancer (CRPC), despite $\mathrm{ADT}^{5-7}$. Several mechanisms, most of which are AR-dependent, are involved in the development of resistance. These mechanisms include the amplification and/or mutation of $A R$, expression of $A R$ splice variants, increased production of androgens, and changes in the activity or expression of AR coactivators and corepressors $^{7-9}$. However, other, often AR-independent, signals have been implicated in the acquisition of resistance, among them are those triggered by WNT family proteins ${ }^{10}$.

This Review focuses on new findings since our last review of the topic in $2012^{11}$. These data demonstrate that the field of WNT signalling research has progressed both at the level of basic research, in which noncanonical WNT 
signalling is now recognized as an important contributor to prostate cancer progression and new regulators of canonical WNT signalling at the plasma membrane have been identified, and at the clinical level, where WNT signalling might soon receive approval for clinical use, as WNT signalling inhibitors are now in early stage clinical trials ${ }^{12-34}$ (Table 2).

\section{[H1] An overview of WNT signalling}

The WNT family comprises 19 cysteine-rich, secreted lipoglycoproteins that have fundamental roles during embryonic and organ development by regulating stem cell self-renewal and cell proliferation, migration, and differentiation ${ }^{35-37}$. WNTs bind to transmembrane frizzled (FZD) receptors and a variety of coreceptors, including low-density lipoprotein receptor (LRP)4 to LRP6, tyrosine-protein kinase transmembrane receptor ROR1 and ROR2, and tyrosine-protein kinase RYK $(\mathrm{RYK})^{38}$ to activate canonical ( $\beta$-catenindependent) and noncanonical ( $\beta$-catenin-independent) signals (Fig. 1).

A hallmark of canonical WNT signalling is the stabilization and nuclear translocation of the protein $\beta$-catenin. In the absence of WNT ligands, $\beta$-catenin is recruited and degraded by the destruction complex, whose components include axin, glycogen synthase kinase-3 (GSK-3), casein kinase 1 (CK1) and adenomatous polyposis coli protein (APC). WNT binding to FZD receptors and LRP5 and LRP6 coreceptors results in the phosphorylation of the latter by CK1 and GSK-3 and recruitment of axin and dishevelled (DVL) to the plasma membrane, thereby disrupting the destruction complex. This disruption results in the stabilization of $\beta$-catenin, which accumulates in the cytoplasm and enters the nucleus, binding to T-cell factor/lymphoid enhancer-binding factor 1 (TCF/LEF) family transcription factors and coactivators, such as the CREBbinding protein (CBP)-histone acetyltransferase p300 (p300 HAT) family and B-cell lymphoma 9 protein (BCL9) and B-cell lymphoma 9-like protein (BCL9L), and regulating the expression of WNT target genes ${ }^{39}$ (Fig. 1).

A novel branch of WNT signalling, WNT-dependent stabilization of proteins $\left(\right.$ WNT-STOP) ${ }^{40}$, was described in 2014. In this signalling cascade, the signal is initiated by WNT binding to LRP6 but the effects are transcriptionindependent, involving cyclin-Y, rather than $\beta$-catenin ${ }^{40}$. WNT-STOP signals 
promote protein stabilization at mitosis. The targets are involved cell-cycle progression, endolysosomal biogenesis, DNA remodelling and the cytoskeleton, so WNT-STOP signals could be important in cancer initiation and progression $^{41}$ (Fig. 1).

Noncanonical WNT signals are less well defined than canonical signals. Noncanonical signals are traditionally subdivided into planar cell polarity (PCP) and WNT-Ca ${ }^{2+}$ pathways $^{39}$, although additional $\beta$-catenin- and TCFindependent signals also exist ${ }^{42}$. Noncanonical WNT signals are activated upon WNT binding to FZD receptors and tyrosine-kinase-like coreceptors, resulting in the recruitment and activation of DVL. The PCP pathway has two parallel branches involving small GTPases: Rho, which activates Rho-associated kinase (ROCK) and Rac, which is linked to c-Jun-N-terminal kinase (JNK), and signalling by activator protein 1 (AP-1) family transcription factors. Cytoskeletal and transcriptional changes associated with these small GTPases regulate cell adhesion and migration ${ }^{39,42-44}$. Activation of the WNT- $\mathrm{Ca}^{2+}$ pathway stimulates $\mathrm{Ca}^{2+}$ release from the endoplasmic reticulum, promoting activation of $\mathrm{G}$ proteins, protein kinase $\mathrm{C}(\mathrm{PKC})$ and $\mathrm{Ca}^{2+} /$ calmodulin-dependent kinase type II (CaMKII). These events can also result in the activation of transcription factors, such as nuclear factor of activated T-cells (NFAT), which promotes cell growth, survival, invasion, and angiogenesis ${ }^{42,43,45,46}$ (Fig. 1).

In 2010, novel associations were identified between WNT and Hippo signalling, which regulates organ size, tissue homeostasis, and patterning ${ }^{47}$. Hippo signals are transduced by yes-associated protein (YAP), transcriptional coactivator with PDZ-binding motif (TAZ), and TEA domain family transcription factors $(T E A D s)^{48}$. YAP-TAZ signals antagonize canonical WNT signalling by binding to components of the destruction complex, such as $\operatorname{axin}^{49}$, and regulating nuclear translocation of $\beta$-catenin (Fig.1). In addition, a noncanonical WNTYAP-TAZ signalling axis has been described, in which WNT binding to FZD and ROR activates $\mathrm{G}_{12}, \mathrm{G} \alpha_{13}$, Rho, and large tumour suppressor homolog (LATS)1 and LATS2 to induce YAP-TAZ signals and TEAD-dependent transcription ${ }^{50}$. The importance of this alternative WNT signalling pathway in prostate cancer is yet to be examined. 
The specific mechanisms by which WNT proteins stimulate these different responses are not fully elucidated, but are anticipated to involve the binding and activation of distinct WNT receptors ${ }^{51,52}$. FZD family receptors have a role in most WNT signalling pathways. These seven-pass transmembrane proteins have an extracellular, cysteine-rich domain (CRD) that is essential and sufficient for WNT binding ${ }^{53-55}$. The crystal structure of the mouse Fzd8 CRD bound to Xenopus Wnt-8 shows the ligand resembling a hand with the thumb and index finger grasping the receptor. The thumb's palmitoleic acid group projects into a deep groove in the CRD (Site 1) while the finger interacts with a small depression in the CRD (Site 2$)^{56}$ (Fig.2). The lipid thumb domain of Wnt8 interacts with residues conserved among FZD family members, accounting for the promiscuity of WNT-FZD interactions. On the other hand, some Site 2 residues are not conserved, Met149, for example, is present in 5 of 10 mammalian FZD proteins ${ }^{56}$, suggesting that Site 2 interactions are responsible for binding specificity ${ }^{56}$. The structure also suggested a potential binding site for WNT coreceptors: a conserved solvent-exposed patch of 10 residues on the opposite side of Wnt-8 to the FZD-binding site ${ }^{56,38}$ (Fig.2). Additional insight into WNT-FZD interactions comes from two independent structural studies of FZD CRDs in complex with fatty acids, which show that the acyl group promotes FZD CRD dimerization and support a 1:2 stoichiometry model for WNT-FZD complexes $^{57,58}$. Moreover, palmitoylated WNT-5A and WNT-8A stabilize the FZD4-CRD-CRD interaction, suggesting that FZD receptors form signalosomes (multiprotein complexes containing membrane-localized Wnt receptors and cytosolic protein complexes containing AXIN and DVL capable of transmitting the WNT signal) upon WNT binding and that the WNT palmitoleoyl group is crucial for this interaction ${ }^{57}$. Additional studies will be required to determine how these interactions orchestrate WNT signalosome assembly.

Apart from FZD receptors, the single-pass transmembrane WNT receptors LRP5 and LRP6 are best known for transducing $\beta$-catenin-dependent signals. These receptors form a trimeric complex with WNT and FZD that is essential for activation of the canonical pathway ${ }^{38,55}$. By contrast, ROR1 and ROR2 have CRDs related to the FZD CRD and activate noncanonical signals ${ }^{38,42,59}$. In addition, RYK binds WNT proteins via a WNT inhibitory factor (WIF) domain 
and is implicated in canonical and noncanonical signalling ${ }^{38,59}$, and proteintyrosine kinase 7 (PTK7); also known as colon carcinoma kinase 4 (CCK4), which is involved in the PCP pathway and has a less well-defined WNT binding site than RYK, ROR1 and ROR2 ${ }^{60}$. ROR1, ROR2, RYK, and PTK7 have intracellular tyrosine-kinase-like domains but they are most likely pseudokinases because these domains lack key residues found at the catalytic site of active kinases and they are devoid of detectable kinase activity in in vitro assays. Although it remains possible that the conditions for their catalytic activation have not been found, it is more likely that they function in association with FZDs, other WNT receptors and allosteric activation of intracellular and other receptor tyrosine kinases ${ }^{59,61,62}$. By contrast, the ROR-related kinase, muscle, skeletal receptor tyrosine-protein kinase (MuSK), which also binds WNTs via a CRD, is catalytically active ${ }^{38}$, as is CAM-1, the Caenorhabditis elegans ROR homolog, suggesting that the signalling mechanisms of this family of kinases have diverged.

Regulation of WNT signalling by secreted WNT antagonists is more complex than that of the receptors. These antagonists can be divided into two classes: those that bind WNT proteins, such as secreted frizzled-related proteins (sFRPs), WIF-1 and Cerberus, and those that associate with the WNT coreceptors LRP5 and LRP6, namely Dickkopf-related protein (DKK)-1, DKK2 , and DKK-4 ${ }^{63-65}$. DKK-3 is a unique member of this family that does not bind LRP5 or LRP6, but can affect WNT signalling indirectly ${ }^{65}$. Adding further complexity, sFRPs can also bind to FZD receptors and activate or inhibit WNT signalling ${ }^{63,66}$.

Results of studies published between 2013 and 2016 have revealed additional mechanisms of regulation of WNT signalling at the cell membrane ${ }^{64,65,67}$. The transmembrane E3 ubiquitin ligases ZNRF3 and RNF43 inhibit WNT signalling by targeting FZD receptors for ubiquitination and degradation. ZNRF3 and RNF43, in turn, are regulated by R-spondins (RSPO1-RSPO4), which are secreted proteins that enhance WNT signalling by simultaneously binding ZNRF3 and RNF43 and leucine-rich repeat-containing G protein-coupled receptors (LGR4-LGR6) to promote ubiquitination and membrane clearance of ZNRF3 and RNF43, facilitating FZD receptor stabilization ${ }^{67,68}$ (Fig. 3). 


\section{[H1] WNT signalling pathway alterations}

Dysregulation of the WNT signalling pathway has been observed in several types of cancer, and some major alterations have been found in prostate cancer in the past 5 years $(\text { Table } 1)^{10,11,35,69}$.

[H2] Canonical effectors

$\beta$-catenin is the key effector of the canonical WNT pathway. The stability of $\beta$ catenin is tightly regulated by a destruction complex of associated proteins, including axin and APC, which promotes its phosphorylation, ubiquitination, and degradation; the presence of cytoplasmic and/or nuclear $\beta$-catenin provides an indication of dysregulation. By contrast, the pool of $\beta$-catenin at the plasma membrane is protected from degradation by its interaction with cadherins. A considerable proportion of prostate tumours have increased levels of $\beta$-catenin in the cytoplasm and/or nucleus either as a result of gene mutations, or, more frequently, nongenomic changes in the expression of inhibitors and activators of WNT signalling ${ }^{11}$.

Activating mutations in the gene encoding $\beta$-catenin (CTNNB1) and inactivating mutations in the genes that encode proteins in the destruction complex (APC and $A X I N 1)$ increase WNT- $\beta$-catenin signalling in many types of cancer, particularly colorectal cancer, but are infrequent in prostate cancer $^{10,11}$. However, genetic and epigenetic changes have been discovered that activate WNT- $\beta$-catenin signalling and could, therefore, contribute to prostate cancer progression. Genetic changes that activate WNT- $\beta$-catenin signalling are more frequently observed in castration-resistant prostate cancer (CRPC) than in treatment-naive prostate cancer. Recurrent alterations in CTNNB1 were observed in $12 \%$ of CRPC samples ${ }^{70}$. Comparison of CRPC and high-grade, untreated, localized prostate tumours uncovered alterations in APC in $22 \%$ of lethal, castration-resistant tumours and in none of the untreated tumours $^{71}$, and a multi-institutional study of 150 metastatic CRPC tumours revealed genomic alterations affecting $A P C$ and $C T N N B 1$ in $18 \%$ of samples ${ }^{72}$. In addition, analysis of single nucleotide polymorphisms (SNPs) in WNT pathway genes identified links between gene variants of $A P C$ and reduced PSA-free survival $^{73}$ and prostate cancer progression ${ }^{74}$.

$A$ variety of cell systems and mouse models have been used to determine the 
outcome of $\beta$-catenin stabilization in non-malignant prostate cells and prostate cancer cells $s^{10,11}$. Studies in mice show that genetic activation of WNT- $\beta$-catenin signalling by a stabilized form of $\beta$-catenin or by $A p c$ deletion results in highgrade prostate intraepithelial neoplasia (PIN). However, progression to invasive carcinoma requires a second event, for example, overexpression of serine protease hepsin ${ }^{75}$ or deletion of phosphatase and tensin homolog (PTEN) ${ }^{76}$. Association of $\beta$-catenin with binding partners in the nucleus, such as TCF/LEF family transcription factors, protects $\beta$-catenin from the destruction complex by competing with APC and axin for binding to the $\beta$-catenin armadillo repeat domain, as is the case at the plasma membrane. All four TCF/LEF family members are expressed to varying extents in the prostate and in prostate tumours, but LEF1 has been the focus of most studies, as it is upregulated in androgen-independent tumours ${ }^{77}$. LEF1 is a WNT- $\beta$-catenin target gene and also a target gene of transcriptional regulator ERG (ERG), which is upregulated in $\sim 50 \%$ of prostate tumours ${ }^{78}$. A 2016 study comparing $\beta$-catenin and LEF1 levels in prostate tumour microarray samples (TMAs) showed increases in the proportion of cells coexpressing $\beta$-catenin and LEF1 in localized prostate cancer and in tumour metastases, which suggests a role for $\beta$-catenin-LEF1mediated transcription in both malignant transformation and metastasis of prostate cancer ${ }^{79}$.

TCF/LEF family members are the key mediators of $\beta$-catenin-dependent transcription, other transcription factors interact with $\beta$-catenin in specific cell types and tissues. The AR is a crucial partner for $\beta$-catenin in prostate cancer. Given the influence of $A R$ in prostate cancer, the importance and consequences of this interaction have been studied in detail ${ }^{11,80,81}$. Coexpression of AR and cytoplasmic $\beta$-catenin in patient tumour samples correlates with high primary Gleason grade (4-5), disease progression, and PSA levels in patients ${ }^{82}$, and AR and WNT signalling pathways are enriched in patients with early-onset (diagnosed at $\leq 50$ years of age) prostate cancer ${ }^{83}$. In mice, the overexpression of AR and stabilized $\beta$-catenin in prostate epithelial cells accelerates tumour development and invasion and reduces survival, suggesting that increased AR signalling enhances $\beta$-catenin-mediated prostate tumour initiation ${ }^{84}$. Castration of these mice resulted in tumour regression, 
implying that $A R$ signalling is also required for tumour maintenance ${ }^{84}$. If and how AR signalling and $\beta$-catenin-dependent signalling work together is not well understood. In this mouse study, both $A R$ and $\beta$-catenin were recruited to regions of the myc proto-oncogene protein (c-Myc) locus containing TCF/LEF family transcription factor binding sites $^{84}$. In addition, gene expression microarray analysis showed that AR overexpression potentiated expression of some genes induced by stabilized $\beta$-catenin, including Myc, Spp1, and Egr1, which promote metastasis. However, it also reduced expression of the direct $\beta$ catenin gene targets Lef1 and Axin $2^{84}$, consistent with previous studies in human cells showing competition between TCF/LEF family transcription factors and $A R$ for binding to $\beta$-catenin ${ }^{10,11}$. The interactions among $A R, \beta$-catenin, and TCF/LEF family transcription factors can be affected by the activation state of $A R$, with hormone deprivation or treatment with the antiandrogen enzalutamide redirecting $\beta$-catenin from AR to TCF-4, leading to activation of WNT- $\beta$-catenin signalling ${ }^{85}$. These observations highlight the pathophysiological relevance and the complexity of the link between AR and WNT- $\beta$-catenin signalling in prostate cancer and suggest that a combination of antiandrogens and WNT inhibitors could improve the effectiveness of current treatments targeting the $\mathrm{AR}^{85}$. Other nuclear proteins might also activate WNT- $\beta$-catenin signalling in hormonedeprived cells, such as the nuclear form of the tyrosine-protein kinase MET, $\mathrm{nMET}^{86}$, and transcription factor SOX (SOX) $-4^{87,88}$.

\section{[H1] WNT ligands and their receptors}

The low frequency of WNT signalling pathway gene mutations in the majority of prostate tumours has encouraged the study of upstream components of the pathway. Novel molecular mechanisms have been discovered that stabilize WNT receptors at the membrane to sustain WNT signals. However, these receptors still require the presence of WNT ligands, the study of which has been hampered by their low expression and/or the lack of specific antibodies. For example, gene expression analysis indicates that WNT1 mRNA is low or undetectable in prostate cancer cell lines ${ }^{78,89,90}$, lower in organ confined (pT2) and non-organ confined ( $\mathrm{pT} 3 / 4$ ) tumours than in benign prostatic hyperplasia, and highly expressed in advanced prostate cancer ${ }^{90}$, whereas 
immunohistochemical analysis dectected high expression of WNT-1 to be highly expressed in prostate cancer cell lines, primary tumours and metastases $^{91}$.

An emerging theme is the activation of noncanonical WNT signalling in advanced prostate cancer and/or in CRPC. WNT-5a is upregulated in prostate cancer and can promote prostate tumour cell invasion through FZD2 and ROR2 ${ }^{92}$. Moreover, Wnt-5a haploinsufficiency in a mouse model of prostate cancer prevents the early onset and early lethality of prostate tumours ${ }^{93}$. However, some reports contradict the protumorigenic effect of WNT-5A, correlating high WNT-5A expression with improved outcomes in localized, lowgrade prostate cancer ${ }^{94-96}$. In other cancers such as liver, breast and lung, the WNT-5A-FZD2 complex has been reported to associate with the protein tyrosine kinase FYN and signal transducer and activator of transcription 3 (STAT3) to promote the epithelial-mesenchymal transition (EMT) and cell migration ${ }^{97}$. One possible explanation for the discrepancy is that the tumoursuppressing role of WNT-5A results from inhibition of canonical signalling and its tumour-promoting role from activation of noncanonical signalling, consistent with association of increased expression of WNT5A and FZD2 with metastasis and biochemical recurrence ${ }^{98}$. Evidence exists that supports a role for WNT-5A in the development of resistance to ADT: WNT5A mRNA is found in circulating tumour cells (CTCs) from patients with CRPC ${ }^{99}$ and from patients with prostate cancer whose disease progressed whilst they were undergoing treatment with the AR inhibitor enzalutamide ${ }^{100}$. WNT-7B, which had been previously observed to be upregulated in prostate cancer ${ }^{101}$, was shown to be an AR target gene in CRPC ${ }^{100}$. WNT-7B activates a noncanonical signal involving PKC and can induce an osteoblastic response in bone ${ }^{102}$. WNT-11 is also upregulated in prostate cancer, but, in contrast to WNT-7B, its expression is repressed by androgens ${ }^{103}$. WNT11 mRNA expression is elevated in tumours from patients receiving $A D T^{104}$ and cell studies show that this WNT is required for prostate cancer cell invasion and neuroendocrine-like differentiation ${ }^{105}$. Many WNTs are observed to be upregulated in certain settings: mRNA expression of WNT5B, WNT6, WNT10A, and WNT16 is increased in tumours from patients after $\mathrm{ADT}^{106}$, and $W N T 2, W N T 3 A$, and WNT11 mRNAs are induced by $\mathrm{ERG}^{78}$, an oncogene expressed in prostate cancer exhibiting TMPRSS2-ERG gene 
fusion $^{107,108}$.

ERG also induces expression of FZD3, FZD5, FZD7, and FZD8 mRNAs ${ }^{109}$, and also FZD4, which has a role in $\mathrm{EMT}^{110}$. Independent studies reported increased expression of FZD8 ${ }^{111}$ and its closest relative, FZD5, in advanced prostate cancer ${ }^{90}$. In addition, SOX9, a critical effector of ERG, is required for increased expression of $F Z D 7^{112}$, which is also upregulated in patients after $A D T^{106}$. Evidence for increased expression of WNT coreceptors in prostate cancer is not as readily available as the evidence for that of the FZD family. However, ROR1 protein was shown to be expressed in 19 of 21 prostate tumours, as well as in many other types of cancer, such as lung, ovarian and colorectal, in which it is linked to increased AKT and CREB phosphorylation and increased proliferation ${ }^{113}$. Together, these studies highlight a limited number of WNTs and WNT receptors as potential therapeutic targets, particularly in the setting of CRPC.

\section{[H1] WNT signalling regulators}

A common theme in prostate cancer is the loss of expression of genes that encode secreted factors that inhibit WNT signalling, usually through promoter methylation. These include genes that encode WNT binding proteins, such as WIF-1 (for which restoration of expression reduces tumour cell motility and reverses $\mathrm{EMT}^{114}$ ) and SFRP1 ${ }^{10,11}$ (expression of which inversely correlates with $\beta$-catenin expression and is a favourable predictive and prognostic biomarker in prostate cancer $\left.{ }^{115}\right)$. Another study showed reduced mRNA expression of SFRP1 and SFRP5 in prostate cancer but an increase in SFRP4 ${ }^{116}$. SFRP2 gene expression is also downregulated in prostate cancer by promoter methylation ${ }^{117,118}$. sFRPs do not always inhibit WNT signalling; for example, sFRP2 potentiates WNT-16B signalling to promote PC3 prostate cancer cell resistance to mitoxantrone, a genotoxic agent frequently administered to prostate cancer patients as a second-line therapy ${ }^{119}$.

Dickkopf proteins can be protumorigenic in some settings, despite their function as WNT inhibitors and the observation that they are frequently silenced in cancer by gene promoter methylation. In prostate cancer, high levels of DKK1 in serum are associated with poor patient prognosis ${ }^{120}$. Furthermore, 
overexpression of DKK-1 promotes prostate tumour growth and the incidence of bone metastases ${ }^{121}$, and induces osteolytic lesions ${ }^{122}$. Some of the effects of DKK-1 have been interpreted in the context of its ability to inhibit canonical signalling, resulting in activation of noncanonical signalling. However, the discovery in 2016 of an unrelated receptor for DKK-1, cytoskeleton-associated protein 4 (CKAP4), indicates that DKK-1 can also enhance cell proliferation independently of its effects on WNT signalling ${ }^{123}$.

Among the other proteins that regulate WNT signalling at the cell surface, mutations in the ubiquitin ligases RNF43 and ZNRF3 and gene fusions that increase expression of RSPO2 were detected at an overall frequency of $6 \%$ in a panel of 150 metastatic CRPC tumours ${ }^{72}$, suggesting novel therapeutic options might be a possibility for some patients with prostate cancer.

\section{[H1] WNT and the tumour microenvironment}

The development and progression of cancer involves several signals that rely on the intrinsic properties of the tumour cells. However the interaction of cancer cells with other cell types in the tumour microenvironment, both in the primary tumour and at sites of metastasis, is also important ${ }^{124}$.

Prostate stromal cells secrete several WNT family members that can influence tumorigenesis and disease progression (Fig. 4). This secretion is exemplified by studies in mice showing that stromal Wnt-3a activates canonical Wnt signalling in the epithelium, facilitating progression of PIN lesions to adenocarcinoma and resistance to androgen deprivation ${ }^{125}$. Stromal overexpression of high mobility group protein HMGI-C in mice was observed to promote development of multifocal PIN lesions that were accompanied by increased expression of Wnt2, Wnt4, and Wnt9a, and could be suppressed by overexpression of $\mathrm{sFRP} 1$ and $\mathrm{Dkk} 1^{126}$. WNT10B is among the genes upregulated in human prostate cancer stroma, and silencing it reduces the protumorigenic effects of stromal cells on LNCaP tumour growth in xenograft assays ${ }^{127}$. WNT signals from the tumour microenvironment are also involved in the development of resistance to therapy. Therapy-induced DNA damage increases the expression of WNT-16B in prostate fibroblasts ${ }^{128}$, in which it acts in a paracrine manner to activate canonical WNT signalling in tumour cells and 
promotes therapy resistance and disease progression ${ }^{128}$. Further studies are required to determine the importance of stromal-derived WNT-16B and of other WNT family members, such as WNT-5A ${ }^{129}$, at different stages of prostate cancer.

\section{[H1] WNT signalling and cancer stem cells}

In prostate and other cancers, such as breast, pancreas, colon, lung and brain, the cancer stem (or progenitor) cell (CSC) population shares many characteristics with somatic stem cells, such as immortality and self-renewal, and is believed to be a source of tumour-initiating cells and also responsible for tumour recurrence, metastasis, and chemoresistance ${ }^{130,131}$. WNT- $\beta$-catenin signalling was shown to promote prostate CSC renewal and expansion in $2009^{132}$. In 2015 , one study showed that shRNA-mediated silencing of the tumour suppressor gene DAB2IP (disabled homolog 2-interacting protein) in human prostate epithelial cells generated CSC with activated WNT- $\beta$-catenin signalling ${ }^{133}$. In this model, WNT- $\beta$-catenin signals directly induced expression of the stem cell marker gene CD44, and inhibitors of WNT secretion synergized with docetaxel to inhibit tumour growth in vivo ${ }^{133}$. In addition, the mRNA and protein expression of ALDH1A, another CSC marker that is also a direct target of WNT- $\beta$-catenin signalling, is elevated in radioresistant prostate cancer cells $^{134}$. Inhibition of WNT- $\beta$-catenin signalling using the tankyrase inhibitor XAV939 or siRNA-mediated knockdown of $\beta$-catenin reduced ALDH1A mRNA and protein levels, reduced the population of ALDH-positive CSCs and increased cancer cell sensitivity to irradiation ${ }^{134}$. These results provide rationale for using inhibitors of WNT- $\beta$-catenin signalling to target prostate CSCs and thereby reduce the development of tumour resistance to therapy ${ }^{135}$.

\section{[H1] Targeting WNT signalling}

The variety of changes observed in WNT pathway components has the potential to provide therapeutic opportunities, particularly in advanced prostate cancer. Several drugs that target WNT signalling are in development (Fig. 5), but very few of them are being tested for the treatment of prostate cancer ${ }^{136}$. This omission might reflect a general impression that WNT signalling has a 
minor role in prostate cancer, based on the low frequency of WNT pathway mutations in primary tumours. The higher frequency of $A P C$ mutations, identification of novel mutations in CRPC, and the increasing evidence that noncanonical WNT signals are active in prostate cancer, are expected to stimulate further interest in this area of drug development.

Specific inhibitors of WNT signalling have been investigated and several FDAapproved drugs in current use affect WNT- $\beta$-catenin signalling ${ }^{137}$, and at least one of these - aspirin - is associated with reduced prostate cancer risk ${ }^{138}$. Specific WNT pathway inhibitors can be classified into functional groups: inhibition of WNT secretion, regulation of antagonists and agonists, targeting WNT receptor interactions, preventing DVL activation, stabilizing the destruction complex and targeting nuclear $\beta$-catenin partners.

[H2] Inhibition of WNT secretion

Porcupine, a membrane-bound O-acetyltransferase, is uniquely responsible for WNT palmitoylation of WNT proteins, which is essential for their secretion ${ }^{139}$. Targeting porcupine has been used extensively to inhibit WNT signalling in different cancer types. The first reported porcupine inhibitors, Inhibitors of WNT Production (IWPs, the best known of which is IWP-2), were identified in a synthetic chemical screen ${ }^{140}$. Several other porcupine inhibitors have since been reported. These inhibitors include WNT-C59, which inhibits growth of WNT-1-expressing mammary tumours in mice ${ }^{141}$; LGK974 ${ }^{142}$, an orally bioavailable inhibitor that reduces tumour growth in rodent models of breast cancer, head and neck cancer ${ }^{142}$, and of xenografts of pancreatic tumours with RNF43 mutations ${ }^{143}$; and ETC-159, another orally bioavailable molecule, which inhibits growth of patient-derived xenografts of colorectal cancers with RSPO fusions $^{144}$. WNT974 (previously known as LGK974) entered a phase I trial in 2011 (still ongoing), for patients with tumours that have mutations in RNF43 and ZNRF3 or RSPO gene fusions ${ }^{12}$. Preliminary clinical data suggested WNT974 has a manageable safety profile and potential for anti-tumour activity $^{145}$. An ongoing phase I/II trial is using WNT974 in combination with the RAF inhibitor LGX818 and the EGFR inhibitor Cetuximab in patients with BRAFV600-mutant KRAS wild-type metastatic colorectal cancer harboring RNF43 mutations or RSPO fusions ${ }^{13}$. ETC-159 (longer name ETC-1922159) 
has also entered a phase I trial in patients with advanced solid tumours ${ }^{14}$ and preliminary data indicate that it is safe and well-tolerated and dose escalation is ongoing ${ }^{146}$ (Table 2). The identification of RNF43 and ZNRF3 mutations and $R S P O 2$ gene fusions in $\mathrm{CRPC}^{72}$ in 2015 provides hope that porcupine inhibitors might also be assessed in patients with advanced prostate cancer.

[H2] Regulation of antagonists and agonists

Many secreted WNT antagonists are epigenetically silenced in cancer, and drugs that target the epigenetic machinery can restore their expression. For example, treatment of renal cancer cells or breast cancer cells with combined therapy of the histone deacetylase (HDAC) inhibitor romidepsin and the DNA methyltransferase (DNMT) inhibitor decitabine reactivates SFRP1 expression to inhibit growth and induce apoptosis in an sFRP1-dependent manner ${ }^{147}$. Application of recombinant sFRP1 proteins could also be a therapeutic option $^{148}$, as is the case for DKK-3, which preclinical studies have shown is an effective treatment for prostate cancer and other cancers, including breast cancer, gastric carcinoma and malignant mesothelioma ${ }^{149}$. A phase I/II clinical trial started in 2013 using an adenoviral vector expressing DKK-3 in patients with localized prostate cancer $^{15}$ have reported promising results, showing reduced metastatic tumour growth in a case study of a patient with treatmentresistant disease and anti-tumour activity and reduced biochemical recurrencefree survival in patients with high-risk localised prostate cancer ${ }^{150,151}$ (Table 2).. Another approach to targeting tumours that contain RSPO fusions is to use function-blocking antibodies; as has been done for RSPO3 in colorectal cancer $^{152}$. RSPO3 antibodies (OMP131R10) are now in phase I clinical trials for advanced solid tumours and metastatic colorectal cancer with results expected in $2018^{16}$ (Table 2).

[H2] Targeting WNT receptor interactions

WNT ligands and their receptors are attractive targets for therapy because they are accessible to monoclonal antibodies and small molecules ${ }^{153}$. WNT-5A has been targeted using antibodies and a WNT-5A-derived peptide called Foxy-5. The WNT-5A antibodies reduce metastasis of gastric tumour cells ${ }^{154}$ but have not been tested for their effects on prostate cancer metastasis. These antibodies do not block WNT receptor binding, but they inhibit WNT-5A-induced internalization of FZD2 and ROR2 ${ }^{155}$. Foxy-5 is a formylated hexapeptide that 
inhibits breast cancer metastasis ${ }^{156,157}$. The first phase I trial failed to reach a maximum tolerated dose $^{17}$, so a second trial is recruiting patients with metastatic breast, colon, or prostate $\operatorname{cancer}^{18}$ (Table 2). Given that the antibodies inhibit WNT-5A signalling and Foxy-5 activates it, and in light of the contrasting reports on the prognosis of high WNT-5A expression in prostate cancer, stratifying patients before using treatments that target WNT-5A will be important.

Antibodies are not the only tool for targeting WNT proteins: a recombinant fusion of the ligand-binding domain of FZD8 and the crystallisable fragment domain of a human IgG1 (FZD8-Fc, also known as OMP-54F28 and Ipafricept) is a decoy WNT receptor that inhibits the proliferation of CSCs and induces tumour differentation ${ }^{158}$. In a phase la clinical trial, this drug was well tolerated and demonstrated evidence of Wnt pathway modulation and potential early single-agent activity manifested by prolonged stable disease ${ }^{19,159}$. It is now being trialled in combination with other drugs in ovarian ${ }^{20,160}$, $\operatorname{liver}^{21}$ and pancreatic cancer ${ }^{22}$ (Table 2).

The success of porcupine inhibitors in blocking all WNTs and the possibility of redundancy among members of the WNT family in cancer has led to increased efforts to target WNT receptors, rather than WNT proteins. FZD7 is one of most frequently upregulated WNT receptors in many cancers, including intestinal cancer, hepatocellular carcinoma, gastric cancer and breast cancer, and it has been targeted using both decoy receptor and antibody approaches ${ }^{161}$. Vantictumab (OMP-18R5) targets FZD1, FZD2, FZD5, FZD7, and FZD8. In preclinical models, it reduces CSC frequency and induces differentiation of tumorigenic cells to cell types that are less tumorigenic and/or more susceptible to conventional chemotherapy. It exhibits strong anti-tumour activity in combination with other approved therapies in patient-derived xenograft (PDX) models, including cancers of the pancreas, breast, lung, liver, ovary and colon $^{162}$. Phase lb clinical trials of vantictumab in combination with standard-ofcare chemotherapy have been carried out in HER2-negative breast cancer and advanced pancreatic cancer ${ }^{23-26}$ (Table 2). In 2017, vantictumab and ipafricept were shown to potentiate the effects of taxanes in PDX models. This involved sensitization of cancer cells to taxanes and required treatment with WNT inhibition prior to mitotic blockade with paclitaxel ${ }^{163}$. This combination strategy 
has been incorporated into ongoing clinical trials of ipafricept and vantictumab with other chemotherapeutic agents ${ }^{20,22,25,26}$.

Other FZD antibodies are patented for the treatment of cancer, for example there were plans to test OTSA101, a radiolabelled antibody against FZD10 ${ }^{164}$, in phase I trials for synovial sarcoma was found to be feasible and safe but the number of patients accrued was too small to continue the study ${ }^{27,165}$ (Table 2). In 2016, phage display was used to generate antibodies that recognise FZD5 and FZD8 that inhibit the growth of RNF43-mutant pancreatic tumour cells in vivo $^{166}$.

Among the non-FZD family receptors being targeted for therapy, LRP6 and ROR1 might be relevant to prostate cancer. The antihelminthic drug niclosamide has been reported to induce apoptosis in prostate cancer by targeting LRP6 ${ }^{167}$. However, this therapy was also shown to downregulate oncogenic variants of $A R$ and overcome enzalutamide resistance in CRPC $^{168,169}$, so whether its effects relate to LRP6 or AR, or both, is unclear. Other agents that target LRP6 exist and can affect prostate cancer cells, including salinomycin, which induces LRP6 degradation ${ }^{170}$, and Mesd, which acts as a chaperone for LRP5 and LRP6 and inhibits prostate tumour xenograft growth $^{171}$. ROR1 expression is increased in a number of cancers, including prostate cancer ${ }^{113,172}$. Given the importance of ROR1 in chronic lymphocytic leukaemia, a variety of approaches have been used to target it, including antibodies, chimeric antigen receptor T cells, and antibody-drug conjugates ${ }^{173}$. Among the antibodies, UC-961 (cirmtuzumab) is recruiting patients for phase I clinical studies for chronic lymphocytic leukaemia ${ }^{28-30}$ and breast cancer ${ }^{31}$ (Table 2).

[H2] Preventing DVL activation

The DVL PDZ domain binds to the carboxyl terminal region of FZD receptors and is essential for signal transduction. Among the three DVL family members, DVL2 is upregulated in prostate tumours and silencing it inhibits prostate cancer cell proliferation and migration ${ }^{174}$. A number of DVL inhibitors have been reported, one of which has been shown to inhibit proliferation of the prostate cancer cell line PC- $3^{175}$.

[H2] Stabilizing the destruction complex 
Tankyrases 1 and 2 are poly (ADP-ribose) transferases (PARPs) that target axin1 and axin2 for proteasomal degradation. Their inhibitors are widely used to promote $\beta$-catenin degradation, thereby inhibit canonical WNT signalling ${ }^{176}$. Several structurally distinct tankyrase inhibitors are now being developed for possible clinical use. Structure-based optimization of one of these, XAV939, resulted in the development of a more selective and orally bioavailable inhibitor, NVP-TNKS656, which inhibited WNT signalling in mouse mammary tumour virus (MMTV)-WNT-1 tumour-bearing mice ${ }^{177}$. Evidence exists that chronic WNT stimulation, which increases expression of the $\beta$-catenin partners LEF1 and B-cell CLL/lymphoma 9-like protein (BCL9L), renders tumour cells resistant to tankyrase inhibition because they shield $\beta$-catenin from $\operatorname{axin}^{178}$. This shielding might occur in prostate tumours that express high levels of LEF1 ${ }^{79}$. Finally, it should be noted that tankyrase inhibitors might have effects not directly related to WNT signalling, as tankyrases bind and regulate several other proteins, including PTEN and angiomotin (AMOT) family proteins $^{176,179,180}$.

[H2] Targeting nuclear $\beta$-catenin partners

Transcriptional activation by $\beta$-catenin requires interaction both with TCF/LEF family transcription factors and other coactivators, such as CBP or p300, which associate with the carboxyl terminal transactivation domain in $\beta$-catenin. Thus, the disruption of these interactions might provide new therapies. Small molecule inhibitors of $\beta$-catenin-responsive transcription have been identified that disrupt the $\beta$-catenin-TCF4 interaction, including the inhibitors of catenin responsive transcription (iCRTs) ${ }^{181}$, BC21, which was identified by virtual docking studies using a compound library and the crystal structures of $\beta$-catenin alone and in complexes with TCF3 and TCF $4^{182}$, and LF3, a 4-thioureidobenzenesulfonamide derivative identified in a high-throughput screen of 16,000 compounds $^{183}$. In 2004 , ICG-001, a first-in-class modulator of WNT signalling, was observed to inhibit binding of $\beta$-catenin to $\mathrm{CBP}^{184}$, and a derivative, PRI724 , is in phase I clinical trials in different solid tumors ${ }^{32}$ and has been reported to have an acceptable toxicity profile ${ }^{185}$. Results are anticipated from completed phase I trials in patients with pancreatic cancer ${ }^{33}$ and leukemia ${ }^{34}$ (Table 2). In addition, a compound named Windorphen has been identified that prevents 
p300 binding to $\beta$-catenin and reduces the viability of PC3 and DU145 cells in vitro $^{186}$. Both CBP and p300 have many other partners, so these compounds also have WNT-independent effects that can lead to induction of caspase-3 dependent apoptosis and cell-cycle arrest ${ }^{187}$. Two further inhibitors that affect $\beta$-catenin-dependent transcription are triptonide, a small molecule identified from the traditional Chinese medicine Tripterygium wilfordii that targets the $\mathrm{C}$ terminal domain of $\beta$-catenin ${ }^{188}$, and an orally bioavailable WNT inhibitor that acts at or downstream of TCF, identified in a cell-based screen ${ }^{189}$. The former has been shown to promote apoptosis of cancer cells, including PC3 and DU145 prostate cancer cells ${ }^{188}$ and the later inhibited tumour growth in a colon cancer xenografts ${ }^{189}$, suggesting they have therapeutic potential.

Given the number of studies on the interaction between $\beta$-catenin with $A R$, the fact that no drug screens targeting this complex have been performed is surprising. However, a group of investigators used the overlap of the interaction domains of AR and TCF-4 on $\beta$-catenin and observed that $\mathrm{ICRT} 3^{181}$ inhibited both AR and WNT- $\beta$-catenin signalling and reduced prostate tumour growth in vivo $^{190}$. The effect of iCRT3 on AR binding to target genes was accompanied by a reduction in binding of coactivator-associated arginine methyltransferase 1 (CARM1 also known as PRMT4), a cofactor for AR and $\beta$-catenin and another therapeutic target ${ }^{190}$.

\section{[H1] Conclusions}

WNT signalling has fundamental roles in prostate carcinogenesis. Both autocrine signalling in tumour cells and paracrine signalling from the tumour microenvironment are involved in prostate tumorigenesis, metastasis, and therapy resistance. Given the possibility that drugs that specifically target WNT signalling components will reach the clinic, the question that arises is whether canonical or noncanonical WNT signals are more critical in prostate cancer. The answer might be tumour stage-dependent and context dependent. Canonical WNT signals could be more important to support prostate cancer stem (or progenitor) cell proliferation and/or survival, than noncanonical signals, particularly under conditions of androgen deprivation, whereas noncanonical WNT signals, by endowing tumour cells with migratory and/or invasive 
properties, might be more important at early stages of tumour spread. Both could be critical in metastatic CRPC, in which both activating mutations in canonical WNT signalling and activated noncanonical WNT signalling have been observed. Several agents that target WNT signalling at different levels of the pathway have been developed, and some of these have reached clinical trials (Table 2). However, not many of them have been tested as possible therapies for prostate cancer. Mutations in CTNNB1 and APC are relatively infrequent in primary tumours, but they are more prevalent than originally thought in advanced tumours and CRPC, and are accompanied by increased noncanonical WNT signalling. In addition, novel WNT pathway mutations have been discovered in CRPC. Together, these new discoveries provide hope for a subset of patients who might benefit from drugs currently in clinical trials that inhibit WNT signalling, particularly those affecting WNT secretion and/or WNT receptor binding, as well as those preventing $\beta$-catenin interaction with key transcription factors, such as LEF1 and AR.

\section{References}

1. Siegel, R., Miller, K. \& Jemal, A. Cancer Statistics, 2016. CA. Cancer J. Clin. 66, 7-30 (2016).

2. Karen E. Livermore, Munkley, J. \& Elliott, D. J. Androgen receptor and prostate cancer. AIMS Mol. Sci. 3, 280-299 (2016).

3. Zhou, Y., Bolton, E. C. \& Jones, J. O. Androgens and androgen receptor signaling in prostate tumorigenesis. J. Mol. Endocrinol. 54, R15-R29 (2015).

4. Mottet, N. et al. Guidelines on Prostate Cancer. Eur. Assoc. Urol. (2016). doi:10.1016/j.eururo.2007.09.002

5. Feldman, B. J. \& Feldman, D. The development of androgenindependent prostate cancer. Nat Rev Cancer 1, 34-45 (2001).

6. Hotte, S. J. \& Saad, F. Current management of castrate-resistant prostate cancer. Curr. Oncol. 17, 72-79 (2010).

7. Chandrasekar, T., Yang, J. C., Gao, A. C. \& Evans, C. P. Mechanisms of resistance in castration-resistant prostate cancer ( CRPC ). Transl Androl Urol 4, 365-380 (2015). 
8. Karantanos, T., Corn, P. G. \& Thompson, T. C. Prostate cancer progression after androgen deprivation therapy: mechanisms of castrate resistance and novel therapeutic approaches. Oncogene 32, 5501-11 (2013).

9. Watson, P. A., Arora, V. K. \& Sawyers, C. L. Emerging mechanisms of resistance to androgen receptor inhibitors in prostate cancer. Nat. Rev. Cancer 15, 701-11 (2015).

10. Yokoyama, N. N., Shao, S., Hoang, B. H., Mercola, D. \& Zi, X. Wnt signaling in castration-resistant prostate cancer: implications for therapy. Am J Clin Exp Urol 2, 27-44 (2014).

11. Kypta, R. M. \& Waxman, J. Wnt/ $\beta$-catenin signalling in prostate cancer. Nat. Rev. Urol. 9, 418-428 (2012).

12. US National Library of Medicine. ClinicalTrials.gov https://clinicaltrials.gov/ct2/show/ NCT01351103 (2017).

13. US National Library of Medicine. ClinicalTrials.gov https://clinicaltrials.gov/ct2/show/ NCT02278133 (2017).

14. US National Library of Medicine. ClinicalTrials.gov https://clinicaltrials.gov/ct2/show/ NCT02521844 (2017).

15. US National Library of Medicine. ClinicalTrials.gov https://clinicaltrials.gov/ct2/show/ NCT01931046 (2015).

16. US National Library of Medicine. ClinicalTrials.gov https://clinicaltrials.gov/ct2/show/ NCT02482441 (2017).

17. US National Library of Medicine. ClinicalTrials.gov https://clinicaltrials.gov/ct2/show/ NCT02020291 (2016).

18. US National Library of Medicine. ClinicalTrials.gov https://clinicaltrials.gov/ct2/show/ NCT02655952 (2016).

19. US National Library of Medicine. ClinicalTrials.gov https://clinicaltrials.gov/ct2/show/ NCT01608867 (2016).

20. US National Library of Medicine. ClinicalTrials.gov https://clinicaltrials.gov/ct2/show/ NCT02092363 (2017).

21. US National Library of Medicine. ClinicalTrials.gov https://clinicaltrials.gov/ct2/show/ NCT02069145 (2017).

22. US National Library of Medicine. ClinicalTrials.gov https://clinicaltrials.gov/ct2/show/ NCT02050178 (2017). 
23. US National Library of Medicine. ClinicalTrials.gov https://clinicaltrials.gov/ct2/show/ NCT01345201 (2016).

24. US National Library of Medicine. ClinicalTrials.gov https://clinicaltrials.gov/ct2/show/ NCT01957007 (2017).

25. US National Library of Medicine. ClinicalTrials.gov https://clinicaltrials.gov/ct2/show/ NCT01973309 (2017).

26. US National Library of Medicine. ClinicalTrials.gov https://clinicaltrials.gov/ct2/show/ NCT02005315 (2017).

27. US National Library of Medicine. ClinicalTrials.gov https://clinicaltrials.gov/ct2/show/ NCT01469975 (2017).

28. US National Library of Medicine. ClinicalTrials.gov https://clinicaltrials.gov/ct2/show/ NCT02222688 (2017).

29. US National Library of Medicine. ClinicalTrials.gov https://clinicaltrials.gov/ct2/show/ NCT02860676 (2017).

30. US National Library of Medicine. ClinicalTrials.gov https://clinicaltrials.gov/ct2/show/ NCT03088878 (2017).

31. US National Library of Medicine. ClinicalTrials.gov https://clinicaltrials.gov/ct2/show/ NCT02776917 (2017).

32. US National Library of Medicine. ClinicalTrials.gov https://clinicaltrials.gov/ct2/show/ NCT01302405 (2015).

33. US National Library of Medicine. ClinicalTrials.gov https://clinicaltrials.gov/ct2/show/ NCT01764477 (2015).

34. US National Library of Medicine. ClinicalTrials.gov https://clinicaltrials.gov/ct2/show/ NCT01606579 (2017).

35. Clevers, $\mathrm{H}$. Wnt/ $\beta$-Catenin Signaling in Development and Disease. Cell 127, 469-480 (2006).

36. Klaus, A. \& Birchmeier, W. Wnt signalling and its impact on development and cancer. Nat. Rev. Cancer 8, 387-398 (2008).

37. Logan, C. \& Nusse, R. The Wnt signaling pathway in development and disease. Annu Rev Cell Dev Biol 20, 781-810 (2004).

38. Niehrs, C. The complex world of WNT receptor signalling. Mol. cell Biol. 13, 767-79 (2012).

39. Komiya, Y. \& Habas, R. Wnt signal transduction pathways.

Organogenesis 4, 68-75 (2008). 
40. Acebron, S. P., Karaulanov, E., Berger, B. S., Huang, Y. L. \& Niehrs, C. Mitotic Wnt Signaling Promotes Protein Stabilization and Regulates Cell Size. Mol. Cell 54, 663-674 (2014).

41. Acebron, S. P. \& Niehrs, C. $\beta$-Catenin-Independent Roles of Wnt/LRP6 Signaling. Trends Cell Biol. 1-12 (2016). doi:10.1016/j.tcb.2016.07.009

42. van Amerongen, R. Alternative Wnt pathways and receptors. Cold spring Harb Perspect Biol 2012 4, (2012).

43. Veeman, M. T., Axelrod, J. D. \& Moon, R. T. A Second Canon: Functions and Mechanisms of $\beta$-Catenin-Independent Wnt Signaling. Dev. Cell 5, 367-377 (2003).

44. Eferl, R. \& Wagner, E. F. AP-1: a double-edged sword in tumorigenesis. Nat. Rev. Cancer 3, 859-68 (2003).

45. Kohn AD, M. R. Wnt and calcium signaling: beta-catenin-independent pathways. Cell Calcium 38, 439-446 (2005).

46. Mancini, M. \& Toker, A. NFAT proteins: emerging roles in cancer progression. Nat. Rev. Cancer 9, 810-20 (2009).

47. Varelas, X. et al. The Hippo Pathway Regulates Wnt/ß-Catenin Signaling. Dev. Cell 18, 579-591 (2010).

48. Piccolo, S., Dupont, S. \& Cordenonsi, M. The Biology of YAP/TAZ: Hippo Signaling and Beyond. Physiol. Rev. 94, 1287-312 (2014).

49. Azzolin, L. et al. YAP/TAZ incorporation in the $\beta$-catenin destruction complex orchestrates the Wnt response. Cell 158, 157-170 (2014).

50. Park, H. W. et al. Alternative Wnt Signaling Activates YAP/TAZ. Cell 162, 780-794 (2015).

51. Anastas, J. N. \& Moon, R. T. WNT signalling pathways as therapeutic targets in cancer. Nat. Rev. Cancer 13, 11-26 (2013).

52. van Amerongen, R., Mikels, A. \& Nusse, R. Alternative wnt signaling is initiated by distinct receptors. Sci. Signal. 1, (2008).

53. Schulte, G. International Union of Basic and Clinical Pharmacology. LXXX. The Class Frizzled Receptors. Am. Soc. Pharmacol. Exp. Ther. 62, 632-667 (2010).

54. Dijksterhuis, J. P., Petersen, J. \& Schulte, G. WNT/Frizzled signalling: Receptor-ligand selectivity with focus on FZD-G protein signalling and its physiological relevance: IUPHAR Review 3. Br. J. Pharmacol. 171, 
1195-1209 (2014).

55. MacDonald, B.T \& He, X. Frizzled and LRP5/6 Receptors for Wnt/bCatenin Signaling. Cold spring Harb Perspect Biol 4, (2012).

56. Janda, C. Y., Waghray, D., Levin, A. M., Thomas, C. \& Garcia, K. C. Structural basis of Wnt recognition by Frizzled. Science 337, 59-64 (2012).

57. Nile, A. H., Mukund, S., Stanger, K., Wang, W. \& Hannoush, R. N. Unsaturated fatty acyl recognition by Frizzled receptors mediates dimerization upon Wnt ligand binding. 114, 4147-4152 (2017).

58. Debruine, Z. J. et al. Wnt5a promotes Frizzled-4 signalosome assembly by stabilizing cysteine-rich domain dimerization. Genes Dev 31, 916926 (2017).

59. Green, J. \& Nusse, R. The Role of Ryk and Ror Receptor Tyrosine Kinases in Wnt Signal Transduction. Cold Spring Harb. Perspect. Biol. 6, (2014).

60. Peradziryi, H., Tolwinski, N. S. \& Borchers, A. The many roles of PTK7: A versatile regulator of cell-cell communication. Arch. Biochem.

Biophys. 524, 71-76 (2012).

61. Martinez, S. et al. The PTK7 and ROR2 protein receptors interact in the vertebrate WNT/Planar cell polarity (PCP) pathway. J. Biol. Chem. 290, 30562-30572 (2015).

62. Debebe, Z. \& Rathmell, W. K. Ror2 as a therapeutic target in cancer. Pharmacol. Ther. 150, 143-8 (2015).

63. Kawano, Y. \& Kypta, R. Secreted antagonists of the Wnt signalling pathway. J. Cell Sci. 116, 2627-34 (2003).

64. Malinauskas, T. \& Jones, E. Y. Extracellular modulators of Wnt signalling. Curr. Opin. Struct. Biol. 29, 77-84 (2014).

65. Cruciat, C. M. \& Niehrs, C. Secreted and Transmembrane Wnt Inhibitors and Activators. Cold Spring Harb. Perspect. Biol. 5, 1-26 (2013).

66. Bovolenta, P., Esteve, P., Ruiz, J. M., Cisneros, E. \& Lopez-Rios, J. Beyond Wnt inhibition: new functions of secreted Frizzled-related proteins in development and disease. J. Cell Sci. 121, 737-46 (2008).

67. Hao, H. X., Jiang, X. \& Cong, F. Control of Wnt receptor turnover by R- 
spondin-ZNRF3/RNF43 signaling module and its dysregulation in cancer. Cancers (Basel). 8, 1-12 (2016).

68. Hao, H.-X. et al. ZNRF3 promotes Wnt receptor turnover in an Rspondin-sensitive manner. Nature 485, 195-200 (2012).

69. Polakis, P. Wnt signaling and cancer. Genes Dev 14, 1837-1851 (2000).

70. Beltran, H. et al. Targeted Next-generation Sequencing of Advanced Prostate Cancer Identifies Potential Therapeutic Targets and Disease Heterogeneity. Eur Urol 63, 920-926 (2013).

71. Grasso, C. S. et al. The Mutational Landscape of Lethal Castrate Resistant Prostate Cancer. Nature 487, 239-243 (2012).

72. Robinson, D. et al. Integrative clinical genomics of advanced prostate cancer. Cell 161, 1215-1228 (2015).

73. Huang, S.-P. et al. Association analysis of Wnt pathway genes on prostate-specific antigen recurrence after radical prostatectomy. Ann. Surg. Oncol. 17, 312-22 (2010).

74. Geng, J.-H. et al. Inherited Variants in Wnt Pathway Genes Influence Outcomes of Prostate Cancer Patients Receiving Androgen Deprivation Therapy. Int. J. Mol. Sci. 17, 1970 (2016).

75. Valkenburg, K. C., Hostetter, G. \& Williams, B. O. Concurrent Hepsin overexpression and adenomatous polyposis coli deletion causes invasive prostate carcinoma in mice. Prostate 75, 1579-1585 (2015).

76. Francis, J. C., Thomsen, M. K., Taketo, M. M. \& Swain, A. $\beta$-Catenin Is Required for Prostate Development and Cooperates with Pten Loss to Drive Invasive Carcinoma. PLoS Genet. 9, (2013).

77. Li, Y. et al. LEF1 in androgen-independent prostate cancer: regulation of androgen receptor expression, prostate cancer growth and invasion. Cancer Res. 69, 3332-3338 (2009).

78. Wu, L. et al. ERG is a critical regulator of Wnt/LEF1 signaling in prostate cancer. Cancer Res. 73, 6068-6079 (2013).

79. Bauman, T. M. et al. Expression and colocalization of $\beta$-catenin and lymphoid enhancing factor-1 in prostate cancer progression. Hum. Pathol. 51, 124-133 (2016).

80. Terry, S., Yang, X., Chen, M. W., Vacherot, F. \& Buttyan, R. 
Multifaceted interaction between the androgen and Wnt signaling pathways and the implication for prostate cancer. J. Cell. Biochem. 99, 402-410 (2006).

81. Wang, G., Wang, J. \& Sadar, M. D. Crosstalk between the Androgen Receptor and $\beta$-Catenin in Castrate Resistant Prostate Cancer. Cancer 68, 9918-9927 (2009).

82. Jung, S. J. et al. Clinical Significance of Wnt/beta-Catenin Signalling and Androgen Receptor Expression in Prostate Cancer. World J Mens Heal. 31, 36-46 (2013).

83. Weischenfeldt, J. et al. Integrative Genomic Analyses Reveal an Androgen-Driven Somatic Alteration Landscape in Early-Onset Prostate Cancer. Cancer Cell 23, 159-170 (2013).

84. Lee, S. H. et al. Androgen Signaling Is a Confounding Factor for $\beta-$ catenin- mediated Prostate Tumorigenesis. Oncogene 35, 702-714 (2016).

85. Lee, E., Ha, S. \& Logan, S. K. Divergent androgen receptor and betacatenin signaling in prostate cancer cells. PLoS One 10, 1-16 (2015).

86. Xie, Y. et al. Crosstalk Between Nuclear MET and SOX9/ß-Catenin Correlates with Castration-Resistant Prostate Cancer. Mol Endocrinol 28, 1629-1639 (2014).

87. Yang, M. et al. Estrogen Induces Androgen-Repressed SOX4 Expression to Promote Progression of Prostate Cancer Cells. Prostate 75, 1363-1375 (2015).

88. Bilir, B. et al. SOX4 is essential for prostate tumorigenesis initiated by PTEN ablation. Cancer Res. 76, 1112-1121 (2016).

89. Zhu, H. et al. Analysis of Wnt Gene Expression in Prostate Cancer : Mutual Inhibition by WNT11 and the Androgen Receptor. 64, 79187926 (2004).

90. Thiele, S. et al. Expression profile of WNT molecules in prostate cancer and its regulation by aminobisphosphonates. J. Cell. Biochem. 112, 1593-1600 (2011).

91. Chen, G. et al. Up-regulation of Wnt-1 and beta-catenin production in patients with advanced metastatic prostate carcinoma: potential pathogenetic and prognostic implications. Cancer 101, 1345-56 (2004). 
92. Yamamoto, H. et al. Wnt5a signaling is involved in the aggressiveness of prostate cancer and expression of metalloproteinase. Oncogene 29, 2036-2046 (2010).

93. Takahashi, S. et al. Noncanonical Wnt signaling mediates androgendependent tumor growth in a mouse model of prostate cancer. Proc. Natl. Acad. Sci. 108, 4938-4943 (2011).

94. Khaja, A. S. et al. Elevated Level of Wnt5a Protein in Localized Prostate Cancer Tissue is Associated with Better Outcome. PLoS One 6, e26539 (2011).

95. Thiele, S. et al. WNT5A has anti-prostate cancer effects in vitro and reduces tumor growth in the skeleton in vivo. J. Bone Miner. Reseach 30, 471-480 (2015).

96. Khaja, A. S. S. et al. Emphasizing the role of Wnt5a protein expression to predict favorable outcome after radical prostatectomy in patients with low-grade prostate cancer. Cancer Med. 1, 96-104 (2012).

97. Gujral, T. S. et al. A Noncanonical Frizzled2 Pathway Regulates Epithelial-Mesenchymal Transition and Metastasis. Cell 159, 844-856 (2014).

98. Sandsmark, E. et al. A novel non-canonical Wnt signature for prostate cancer aggressiveness. Oncotarget 8, 9572-9586 (2017).

99. Chen, C. L. et al. Single-cell analysis of circulating tumor cells identifies cumulative expression patterns of EMT-related genes in metastatic prostate cancer. Prostate 73, 813-826 (2013).

100. Miyamoto, D. T. et al. RNA-Seq of single prostate CTCs implicates noncanonical Wnt signaling in antiandrogen resistance. Science (80-. ). 349, 1351-1356 (2015).

101. Li, Z. G. et al. Low-density lipoprotein receptor-related protein 5 (LRP5) mediates the prostate cancer-induced formation of new bone. Oncogene 27, 596-603 (2008).

102. Zheng, D. et al. Role of WNT7B-induced noncanonical pathway in advanced prostate cancer. Mol. Cancer Res. 11, 482-93 (2013).

103. Uysal-Onganer, P. \& Kypta, R. M. Wnt11 in 2011 - the regulation and function of a non-canonical Wnt. Acta Physiol. 204, 52-64 (2012).

104. Volante, M. et al. Androgen deprivation modulates gene expression 
profile along prostate cancer progression. Hum. Pathol. 56, 81-88 (2016).

105. Uysal-Onganer, P. et al. Wnt-11 promotes neuroendocrine-like differentiation, survival and migration of prostate cancer cells. Mol. Cancer 9, 55 (2010).

106. Rajan, P. et al. Next-generation sequencing of advanced prostate cancer treated with androgen-deprivation therapy. Eur. Urol. 66, 32-9 (2014).

107. Tomlins, S. A. et al. Recurrent Fusion of TMPRSS2 and ETS Transcription Factor Genes in Prostate Cancer. Science (80-. ). 310, 644-648 (2005).

108. Perner, S. et al. TMPRSS2-ERG fusion prostate cancer: an early molecular event associated with invasion. Am. J. Surg. Pathol. 31, 882888 (2007).

109. Brase, J. C. et al. TMPRSS2-ERG -specific transcriptional modulation is associated with prostate cancer biomarkers and TGF- $\beta$ signaling. BMC Cancer 11, 507 (2011).

110. Gupta, S. et al. FZD4 as a mediator of ERG oncogene-induced WNT signaling and epithelial-to-mesenchymal transition in human prostate cancer cells. Cancer Res. 70, 6735-6745 (2010).

111. Pascal, L. E. et al. Gene expression relationship between prostate cancer cells of Gleason 3, 4 and normal epithelial cells as revealed by cell type-specific transcriptomes. BMC Cancer 9, 452 (2009).

112. Ma, F. et al. SOX9 drives WNT pathway activation in prostate cancer. J. Clin. Invest. 126, 525-530 (2016).

113. Zhang, $\mathrm{S}$. et al. The onco-embryonic antigen ROR1 is expressed by a variety of human cancers. Am. J. Pathol. 181, 1903-1910 (2012).

114. Yee, D. S. et al. The Wnt inhibitory factor 1 restoration in prostate cancer cells was associated with reduced tumor growth, decreased capacity of cell migration and invasion and a reversal of epithelial to mesenchymal transition. Mol. Cancer 9, (2010).

115. Zheng, L. et al. Diagnostic value of SFRP1 as a favorable predictive and prognostic biomarker in patients with prostate cancer. PLoS One 10, 1-16 (2015). 
116. García-Tobilla, P. et al. SFRP1 repression in prostate cancer is triggered by two different epigenetic mechanisms. Gene 593, 292-301 (2016).

117. O'Hurley, G. et al. The role of secreted frizzled-related protein 2 expression in prostate cancer. Histopathology 59, 1240-1248 (2011).

118. Perry, A. S. et al. Gene expression and epigenetic discovery screen reveal methylation of SFRP2 in prostate cancer. Int. J. Cancer 132, 1771-1780 (2013).

119. Sun, Y. et al. SFRP2 augments WNT16B signaling to promote therapeutic resistance in the damaged tumor microenvironment. Oncogene 35, 4321-34 (2016).

120. Rachner, T. D. et al. High serum levels of Dickkopf-1 are associated with a poor prognosis in prostate cancer patients. BMC Cancer 14, 649 (2014).

121. Thudi, N. K. et al. Dickkopf-1 (DKK-1) stimulated prostate cancer growth and metastasis and inhibited bone formation in osteoblastic bone metastases. Prostate 71, 615-625 (2011).

122. Mazon, M., Masi, D. \& Carreau, M. Modulating Dickkopf-1: A strategy to monitor or treat cancer? Cancers (Basel). 8, 1-9 (2016).

123. Kimura, H. et al. CKAP4 is a Dickkopf1 receptor and is involved in tumor progression. J. Clin. Invest. 126, 2689-2705 (2016).

124. Josson, S., Matsuoka, Y., Chung, L. W. K. \& Zhau, H. E. Tumor stroma co-evolution in prostate cancer progression and metastasis. Semin Cell Dev Biol 21, 26-32 (2010).

125. $\mathrm{Li}, \mathrm{X}$. et al. Prostate tumor progression is mediated by a paracrine TGF$\beta /$ Wnt3a signaling axis. Oncogene 27, 7118-7130 (2008).

126. Zong, Y. et al.. Stromal epigenetic dysregulation is sufficient to initiate mouse prostate cancer via paracrine Wnt signaling. PNAS 109, 33953404 (2012).

127. Dakhova, O., Rowley, D. \& Ittmann, M. Genes upregulated in prostate cancer reactive stroma promote prostate cancer progression in vivo. Clin. Cancer Res. 20, 100-109 (2014).

128. Sun, Y. et al. Treatment-induced damage to the tumor microenvironment promotes prostate cancer therapy resistance through 
WNT16B. Nat. Med. 18, 1359-68 (2012).

129. Lee, G. T. et al. Prostate cancer bone metastases acquire resistance to androgen deprivation via WNT5A-mediated BMP-6 induction. Br. J. Cancer 110, 1634-44 (2014).

130. Packer, J. R. \& Maitland, N. J. The molecular and cellular origin of human prostate cancer. Biochim. Biophys. Acta - Mol. Cell Res. 1863, 1238-1260 (2016).

131. Chen, X., Rycaj, K., Liu, X. \& Tang, D. G. New insights into prostate cancer stem cells. Cell Cycle 12, 579-86 (2013).

132. Bisson, I. \& Prowse, D. M. WNT signaling regulates self-renewal and differentiation of prostate cancer cells with stem cell characteristics. Cell Res. 19, 683-97 (2009).

133. Eun-Jin, Y. et al. Targeting cancer stem cell in castration resistant prostate cancer. Clin Cancer Res 22, 670-679 (2016).

134. Cojoc, M. et al. Aldehyde dehydrogenase is regulated by $\beta$ Catenin/TCF and promotes radioresistance in prostate cancer progenitor cells. Cancer Res. 75, 1482-1494 (2015).

135. Takebe, N. et al. Targeting Notch, Hedgehog, and Wnt Pathways in cancer stem cells: clinical update. Nat Rev Clin Oncol 12, 445-464 (2015).

136. Kahn, M. Can we safely target the WNT pathway? Nat Rev Drug Discov 13, 513-532 (2014).

137. Ahmed, K., Shaw, H. V., Koval, A. \& Katanaev, V. L. A second WNT for old drugs: Drug repositioning against WNT-dependent cancers. Cancers (Basel). 8, 1-27 (2016).

138. Vidal, A. C. et al. Aspirin, NSAID and risk of prostate cancer: Results from the REDUCE study. 21, 756-762

139. Mikels, A. \& Nusse, R. Wnts as ligands: processing, secretion and reception. Oncogene 25, 7461-8 (2006).

140. Chen, B. et al. Small molecule-mediated disruption of Wnt-dependent signaling in tissue regeneration and cancer. Nat Chem Biol 5, 100-107 (2009).

141. Proffitt, K. D. et al. Pharmacological inhibition of the Wnt acyltransferase PORCN prevents growth of WNT-driven mammary cancer. Cancer Res. 
73, 502-507 (2013).

142. Liu, J. et al. Targeting Wnt-driven cancer through the inhibition of Porcupine by LGK974. Proc. Natl. Acad. Sci. 110, 20224-20229 (2013).

143. Jiang, X. et al. Inactivating mutations of RNF43 confer Wnt dependency in pancreatic ductal adenocarcinoma. Proc. Natl. Acad. Sci. U. S. A. 110, 12649-54 (2013).

144. Madan, B. et al. Wnt addiction of genetically defined cancers reversed by PORCN inhibition. Oncogene 35, 2197-2207 (2016).

145. Janku, F. et al. Phase I study of WNT974, a first-in-class Porcupine inhibitor, in advanced solid tumors [abstract]. Mol Cancer Ther (2015).

146. Teneggi, V. et al. A phase 1, first-in-human dose escalation study of ETC-159 in advanced or metastatic solid tumours [Abstract]. (2016).

147. Cooper, S. J. et al. Reexpression of Tumor Suppressor, sFRP1, Leads to Antitumor Synergy of Combined HDAC and Methyltransferase Inhibitors in Chemoresistant Cancers. Mol. Cancer Ther. 11, 2105-2115 (2012).

148. Ghoshal, A., Goswami, U., Sahoo, A. K., Chattopadhyay, A. \& Ghosh, S. S. Targeting Wnt Canonical Signaling by Recombinant sFRP1 Bound Luminescent Au-Nanocluster Embedded Nanoparticles in Cancer Theranostics. ACS Biomater. Sci. Eng. 1, 1256-1266 (2015).

149. Veeck, J. \& Dahl, E. Targeting the Wnt pathway in cancer: The emerging role of Dickkopf-3. Biochim. Biophys. Acta - Rev. Cancer 1825, 18-28 (2012).

150. Kumon, $\mathrm{H}$. et al. Adenovirus vector carrying REIC/DKK-3 gene: neoadjuvant intraprostatic injection for high-risk localized prostate cancer undergoing radical prostatectomy. Cancer Gene Ther. 0, 1-10 (2016).

151. Kumon, $\mathrm{H}$. et al. Ad-REIC gene therapy: Promising results in a patient with metastatic CRPC following chemotherapy. Clin. Med. Insights Oncol. 9, 31-38 (2015).

152. Storm, E. E. et al. Targeting PTPRK-RSPO3 colon tumours promotes differentiation and loss of stem-cell function. Nature 529, 97-100 (2015).

153. Madan, B. \& Virshup, D. M. Targeting Wnts at the Source--New 
Mechanisms, New Biomarkers, New Drugs. Mol. Cancer Ther. 10871095 (2015). doi:10.1158/1535-7163.MCT-14-1038

154. Hanaki, H. et al. An Anti-Wnt5a Antibody Suppresses Metastasis of Gastric Cancer Cells In Vivo by Inhibiting Receptor-Mediated Endocytosis. Mol. Cancer Ther. 11, 298-307 (2012).

155. Shojima, K. et al. Wnt5a promotes cancer cell invasion and proliferation by receptor-mediated endocytosis-dependent and -independent mechanisms, respectively. Sci. Rep. 5, 8042 (2015).

156. Säfholm, A. et al. A formylated hexapeptide ligand mimics the ability of Wnt-5a to impair migration of human breast epithelial cells. J. Biol. Chem. 281, 2740-2749 (2006).

157. Säfholm, A. et al. The Wnt-5a-derived hexapeptide Foxy-5 inhibits breast cancer metastasis in vivo by targeting cell motility. Clin. Cancer Res. 14, 6556-6563 (2008).

158. Le, P., McDermott, J. D. \& Jimeno, A. Targeting the Wnt pathway in human cancers: therapeutic targeting with a focus on OMP-54F28. Pharmacol Ther 0, 1-11 (2015).

159. Jimeno, A. et al. A first-in-human phase 1 study of anticancer stem cell agent OMP-54F28 (FZD8-Fc), decoy receptor for WNT ligands, in patients with advanced solid tumors [poster]. J Clin Oncol (2014).

160. O'Cearbhaill, R. E. et al. Phase 1b of WNT inhibitor ipafricept (IPA, decoy receptor for WNT ligands) with carboplatin $(C)$ and paclitaxel (P) in recurrent platinum-sensitive ovarian cancer (OC)[Abstract]. J Clin Oncol 34, (2016).

161. Phesse, T., Flanagan, D. \& Vincan, E. Frizzled7: A promising achilles' heel for targeting the Wnt receptor complex to treat cancer. Cancers (Basel). 8, 1-33 (2016).

162. Gurney, A. et al. Wnt pathway inhibition via the targeting of Frizzled receptors results in decreased growth and tumorigenicity of human tumors. Proc. Natl. Acad. Sci. U. S. A. 109, 11717-22 (2012).

163. Fischer, M. M. et al. WNT antagonists exhibit unique combinatorial antitumor activity with taxanes by potentiating mitotic cell death. 1-12 (2017).

164. Fukukawa, C. et al. Radioimmunotherapy of human synovial sarcoma 
using a monoclonal antibody against FZD10. Cancer Sci. 99, 432-440 (2008).

165. Anne-Laure Giraudet et al. SYNFRIZZ-A phase la/lb of a radiolabelled monoclonal $\mathrm{AB}$ for the treatment of relapsing synovial sarcoma. $\mathrm{J} \mathrm{NuCl}$ Med 55, (2014).

166. Steinhart, Z. et al. Genome-wide CRISPR screens reveal a Wnt - FZD5 signaling circuit as a druggable vulnerability of RNF43 -mutant pancreatic tumors. Nat. Publ. Gr. (2016). doi:10.1038/nm.4219

167. Lu, W. et al. Niclosamide suppresses cancer cell growth by inducing Wnt co-receptor LRP6 degradation and inhibiting the Wnt/ $\beta$-catenin pathway. PLoS One 6, 1-8 (2011).

168. Liu, C. et al. Niclosamide inhibits androgen receptor variants expression and overcomes enzalutamide resistance in castration resistant prostate cancer. Clin Cancer Res 20, 3198-3210 (2014).

169. Liu, C., Armstrong, C., Zhu, Y., Lou, W. \& Gao, A. C. Niclosamide enhances abiraterone treatment via inhibition of androgen receptor variants in castration resistant prostate cancer. Oncotarget 7, 32210-20 (2016).

170. Lu, W. \& Li, Y. Salinomycin suppresses LRP6 expression and inhibits both $\mathrm{Wnt} / \mathrm{\beta}$-catenin and mTORC1 signaling in breast and prostate cancer cells. J. Cell. Biochem. 115, 1799-1807 (2014).

171. Lin, C. et al. Mesd is a general inhibitor of different Wnt ligands in Wnt/LRP signaling and inhibits PC-3 tumor growth in vivo. FEBS Lett. 585, 3120-3125 (2011).

172. Borcherding, N., Kusner, D., Liu, G. H. \& Zhang, W. ROR1, an embryonic protein with an emerging role in cancer biology. Protein Cell 5, 496-502 (2014).

173. Kolb, R., Kluz, P., Zhang, W., Tyrosine, R. \& Receptor, K. O. ROR1 is an Intriguing Target for Cancer Therapy ROR1-Based Targeted Therapies ROR1-Mediated Oncogenic Signalling. Mol. Enzymol. Drug Targets 2, 1-3 (2016).

174. Yang, Y. et al. Dishevelled-2 silencing reduces androgen-dependent prostate tumor cell proliferation and migration and expression of Wnt-3a and matrix metalloproteinases. Mol. Biol. Rep. 40, 4241-4250 (2013). 
175. Grandy, D. et al. Discovery and characterization of a small molecule inhibitor of the PDZ domain of dishevelled. J. Biol. Chem. 284, 1625616263 (2009).

176. Haikarainen, T., Krauss, S. \& Lehtio, L. Tankyrases: structure, function and therapeutic implications in cancer. Curr. Pharm. Des. 20, 6472-88 (2014).

177. Shultz, M. D. et al. Identification of NVP-TNKS656: The Use of Structure-Efficiency Relationships To Generate a Highly Potent, Selective, and Orally Active Tankyrase Inhibitor. J. Med. Chem. 56, 6495-511 (2013).

178. De La Roche, M., Ibrahim, A. E. K., Mieszczanek, J. \& Bienz, M. LEF1 and $B 9 L$ shield $\beta$-catenin from inactivation by axin, desensitizing colorectal cancer cells to tankyrase inhibitors. Cancer Res. 74, 14951505 (2014).

179. Wang, W. et al. Tankyrase inhibitors target YAP by stabilizing angiomotin family proteins. Cell Rep 13, 524-532 (2015).

180. Li, N. et al. Poly-ADP ribosylation of PTEN by tankyrases promotes PTEN degradation and tumor growth. Genes Dev. 29, 157-170 (2015).

181. Gonsalves, F. C. et al. An RNAi-based chemical genetic screen identifies three small-molecule inhibitors of the Wnt / wingless signaling pathway. Proc. Natl. Acad. Sci. U. S. A. 108, 5954-5963 (2011).

182. Tian, W. et al. Structure-based discovery of a novel inhibitor targeting the beta-catenin/Tcf4 interaction. Biochemistry 51, 724-731 (2012).

183. Fang, L. et al. A small-molecule antagonist of the $\beta$-catenin/TCF4 interaction blocks the self-renewal of cancer stem cells and suppresses tumorigenesis. Cancer Res. 76, 891-901 (2016).

184. Emami, K. H. et al. A small molecule inhibitor of $\beta$-catenin/CREBbinding protein transcription. Proc. Natl. Acad. Sci. 101, 12682-12687 (2004).

185. A phase I first-in-human study of PRI-724 in patients (pts) with advanced solid tumors [abstr 2501]. J Clin Oncol 31, (2013).

186. Hao, J. et al. Selective Small Molecule Targeting $\beta$-Catenin Function Discovered by In Vivo Chemical Genetic Screen. Cell Rep 4, 898-904 (2013). 
187. Bordonaro, M. \& Lazarova, D. L. CREB-binding protein, p300, butyrate, and Wnt signaling in colorectal cancer. World J. Gastroenterol. 21, 8238-8248 (2015).

188. Chinison, J. et al. Triptonide Effectively Inhibits Wnt/ß-Catenin Signaling via C-terminal Transactivation Domain of $\beta$-catenin. Sci. Rep. 6, 32779 (2016).

189. Mallinger, A. et al. Discovery of potent, orally bioavailable, smallmolecule inhibitors of WNT signaling from a cell-based pathway screen. J. Med. Chem. 58, 1717-1735 (2015).

190. Lee, E. et al. Inhibition of androgen receptor and $\beta$-catenin activity in prostate cancer. Proc. Natl. Acad. Sci. U. S. A. 110, 15710-5 (2013). 
Figure 1 | WNT signalling pathways. In the absence of WNT ligands (WNT OFF), $\beta$-catenin is recruited and degraded by the destruction complex (adenomatous polyposis coli protein (APC), axin, glycogen synthase kinase-3 (GSK-3) and casein kinase 1 (CK1)) and yes-associated protein (YAP) and transcriptional coactivator with PDZ-binding motif (TAZ)), which have been linked to WNT signalling, and WNT target genes are repressed. Binding of WNT ligands to frizzled (FZD) and either LRP5 or LRP6 to activate canonical signalling or ROR1, ROR2, RYK, PTK7 or MuSK to activate and noncanonical signalling (WNT ON). Canonical signals disrupt the destruction complex, stabilizing $\beta$-catenin, which enters the nucleus and binds T-cell factor/lymphoid enhancer-binding factor 1 (TCF/LEF) family transcription factors to activate gene expression. The WNT-STOP pathway is a transcription-independent pathway involving low-density lipoprotein receptor (LRP) and cyclin Y. Noncanonical signals activate small GTPases and various kinases, mobilize $\mathrm{Ca}^{2+}$ and activate activator protein 1 (AP-1) family and nuclear factor of activated T-cells (NFAT) transcription factors. New noncanonical signals involve activation of YAP and TAZ, the SRC family tyrosine protein kinase FYN and signal transducer and activator of transcription (STAT) family members. 
Fig 1 WNT OFF

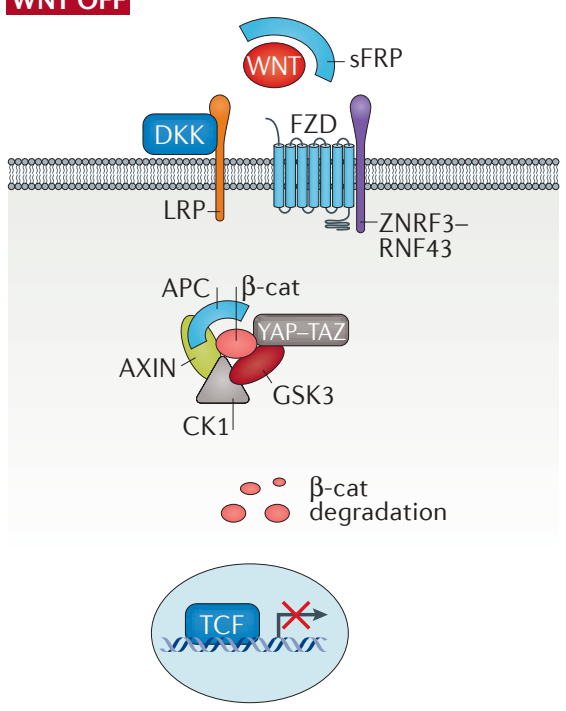

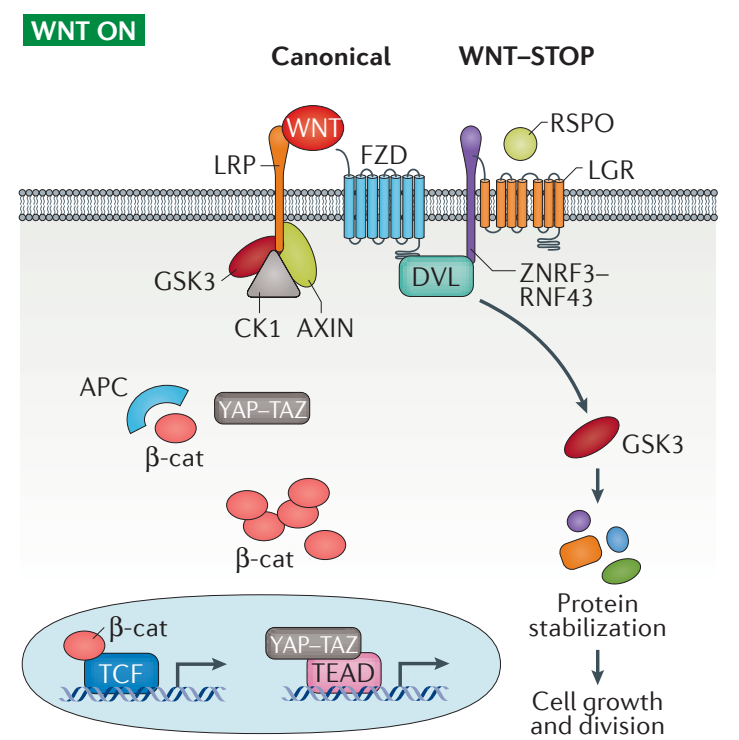

Noncanonical
ROR

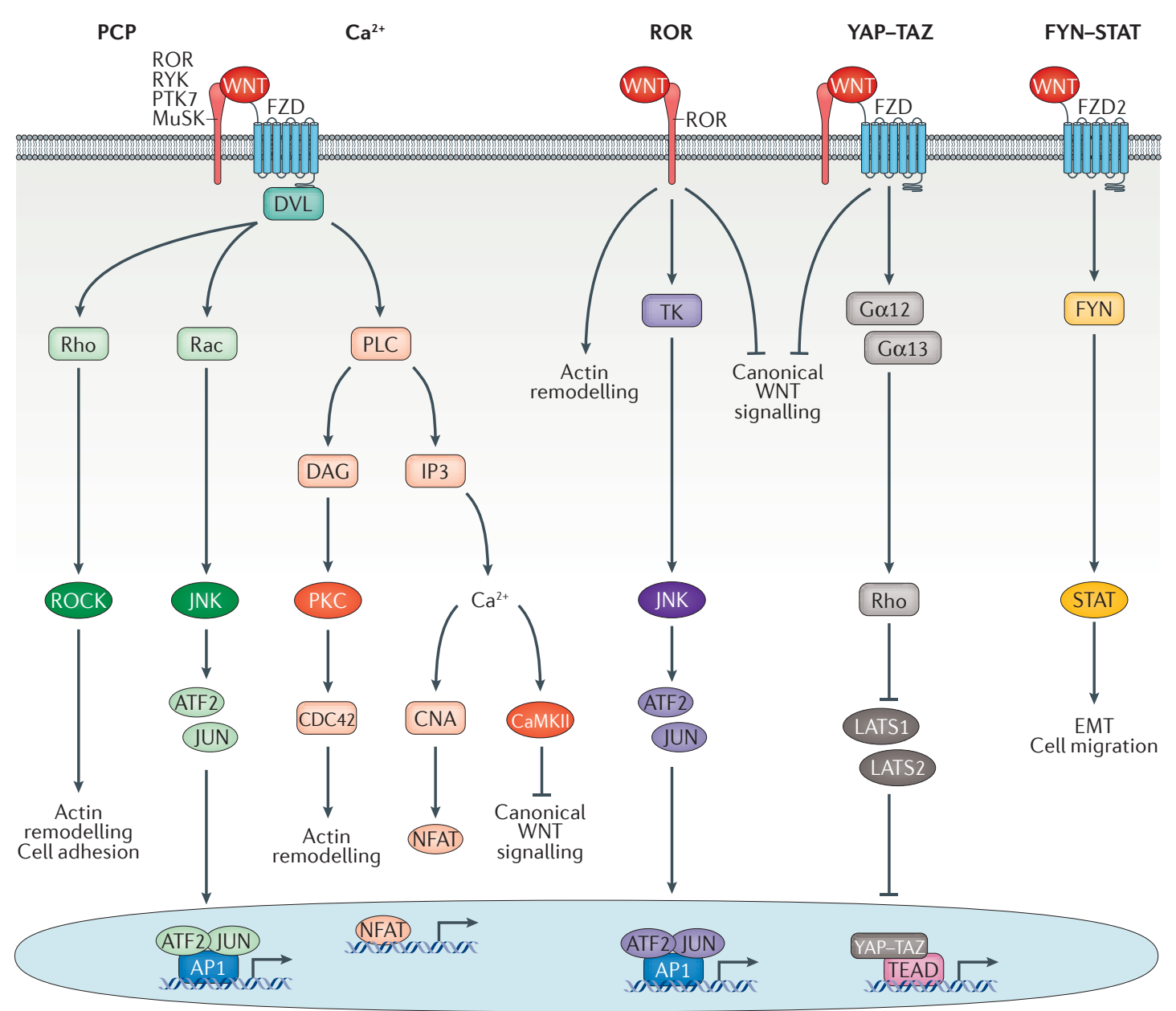




\section{Figure 2 Crystal structure of Wnt8-FZD8 CRD complex}

Representative image of Xenopus wnt8 (purple) bound to FZD8-CRD (blue). The interaction is mediated through the lipid thumb ("Site 1") and the index finger ("Site 2") of wnt8. Sites 1 and 2 are involved in Wnt-FZD promiscuity or specificity, respectively. Patch residues are involved in wht binding to coreceptors leading to ternary complexes. Figure adapted from Reference 38.

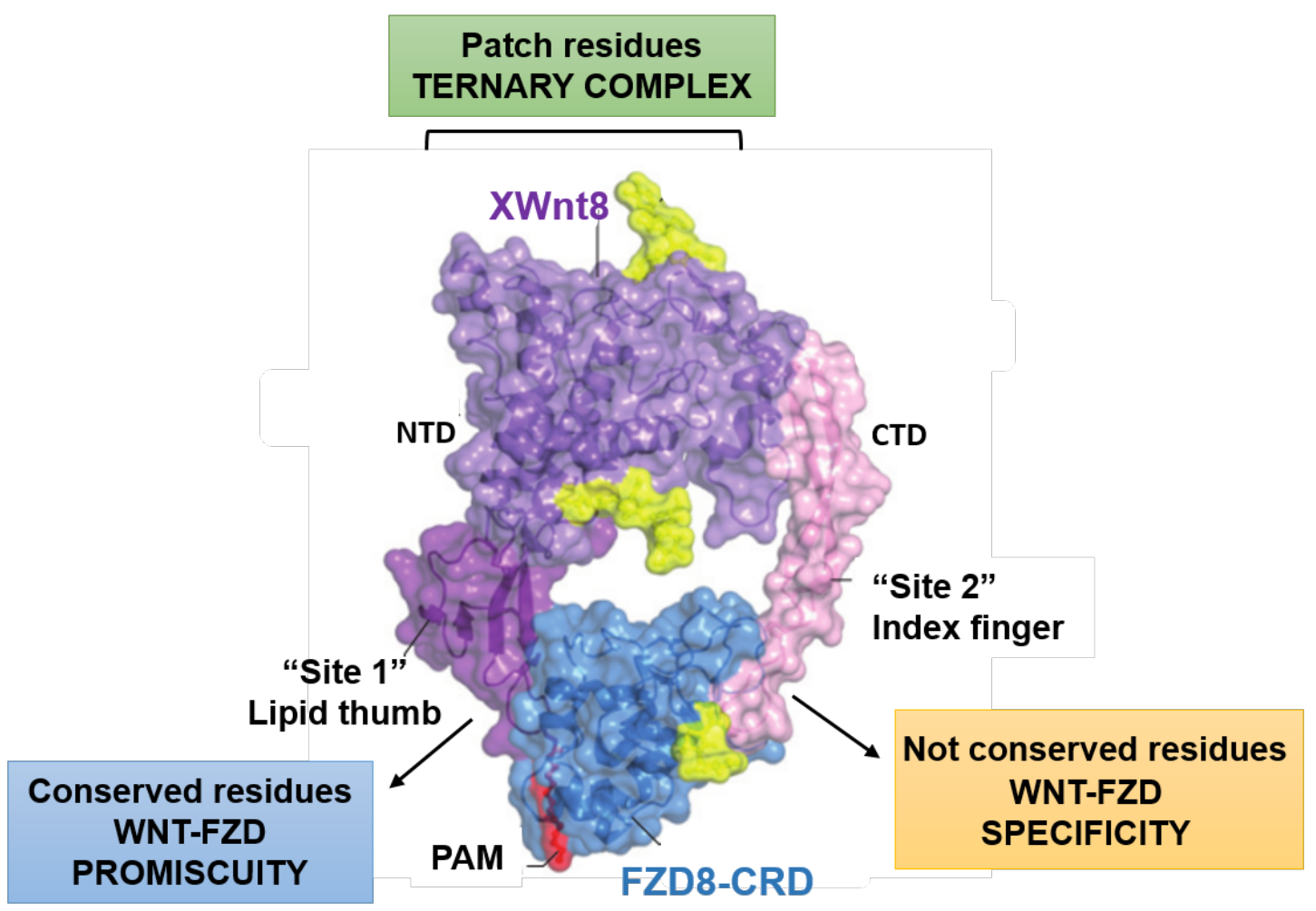


Figure 3 | WNT signalling regulation by RNF43, ZNRF3 and RSPO. RNF43 and ZNRF3 ubiquitin ligases inhibit WNT signalling by ubiquitinating frizzled (FZD) receptors, promoting their degradation. R-spondin (RSPO) binds RNF43 and/or ZNRF3 and leucine-rich repeat-containing G protein-coupled receptors (LGR5), resulting in membrane clearance of RNF43 and ZNRF3 and increased FZD stability. Mutations in RNF43 and ZNRF3 or overexpression of RSPO as a result of a RSPO gene fusion activate WNT signalling. 
Fig 2

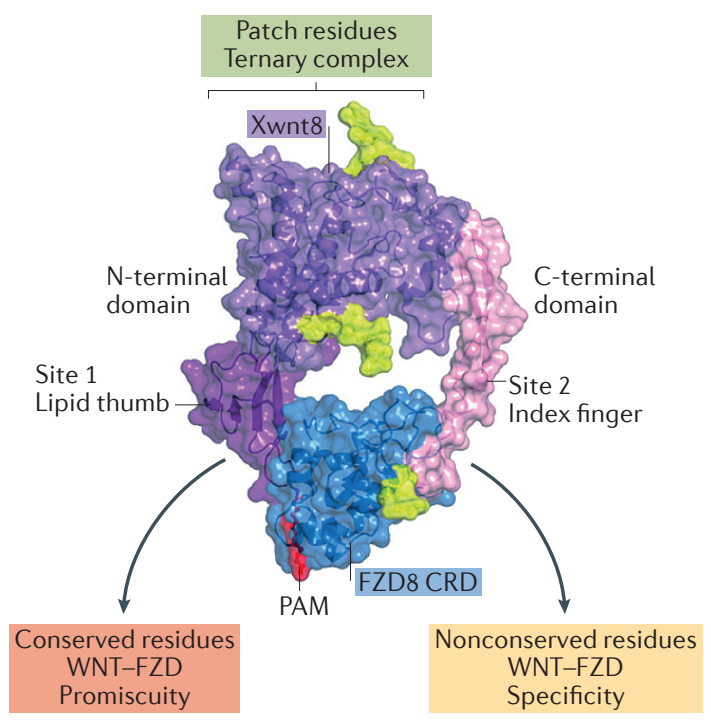

Nature Reviews | Urology

Fig 3

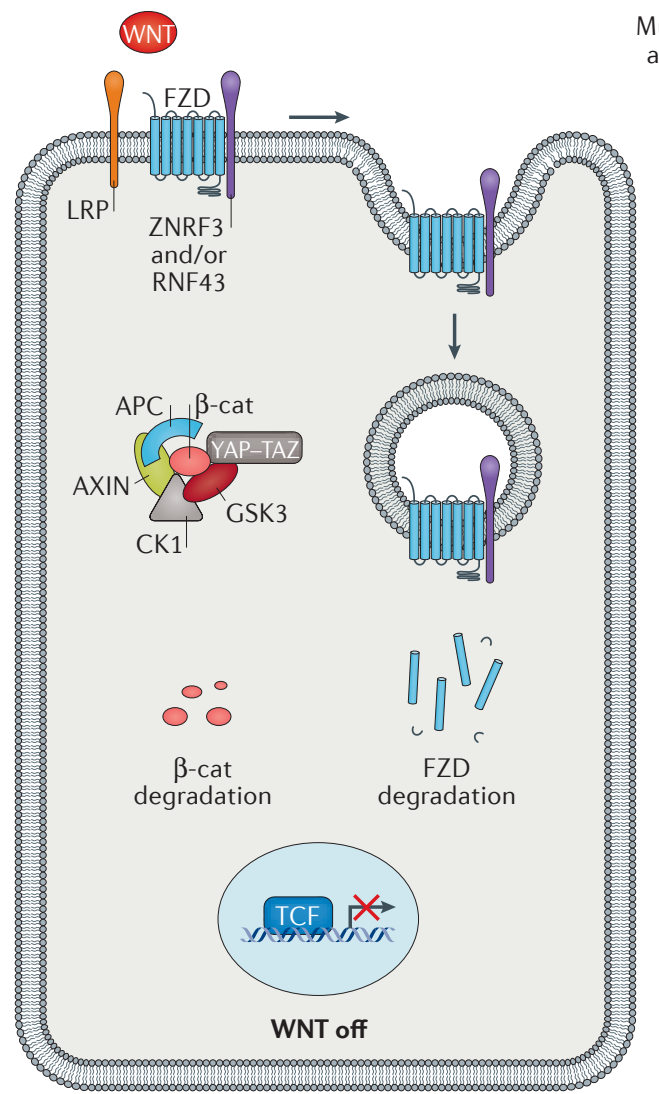

Mutated ZNRF3 and/or RNF43

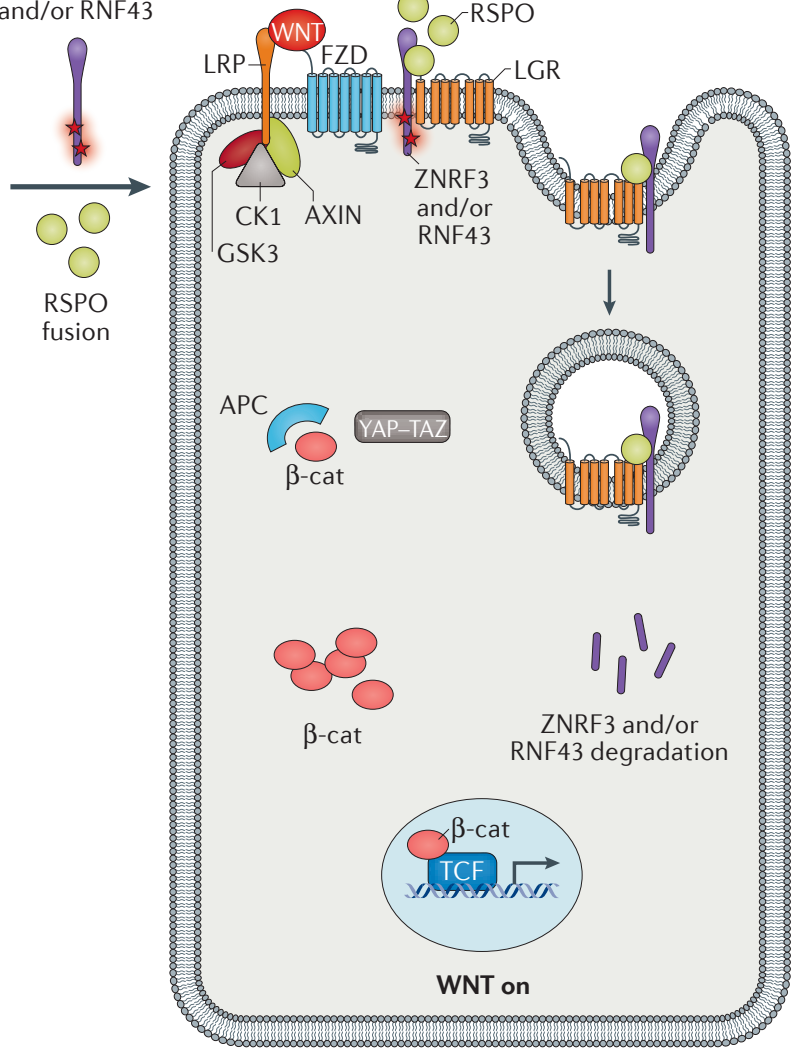

Nature Reviews | Urology 
Figure 4 | Paracrine WNT signals from the tumour microenvironment.

Paracrine WNT signals from the tumour microenvironment can contribute to tumour progression $\left(\mathrm{WNT}-10 \mathrm{~B}^{100}\right)$ and therapy resistance $\left(\mathrm{SFRP} 2^{91}\right.$ and $\mathrm{WNT}-16 \mathrm{~B}^{101}$ or WNT-5A and bone morphogenetic protein (BMP) $6{ }^{102}$ ). 
Fig 4

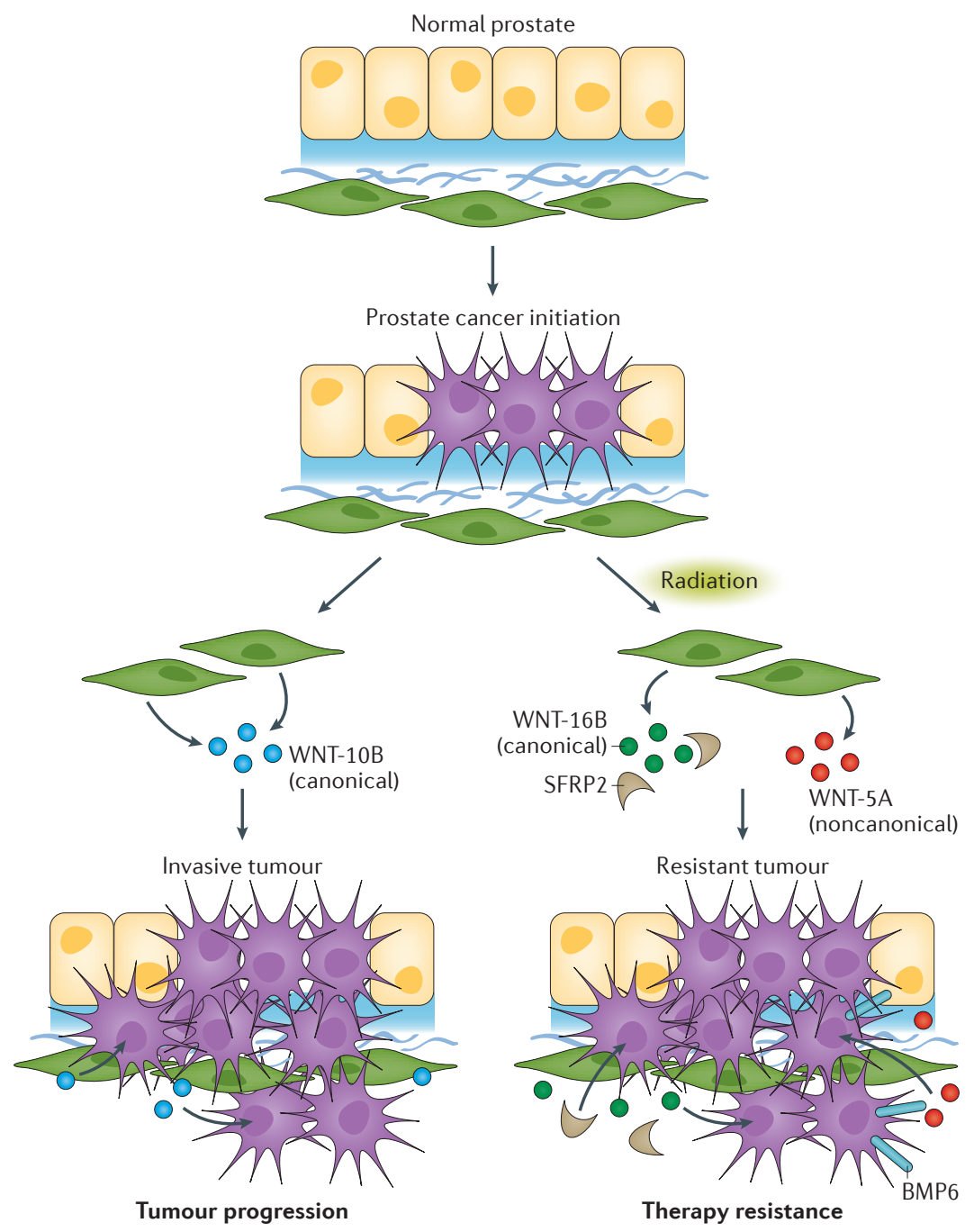

Nature Reviews | Urology 
Figure 5 | Drugs that target WNT signalling. May drugs have been developed that act on different targets at different levels in the WNT signalling pathway. The therapeutics are inhibitors of WNT secretion (red), regulators of WNT antagonist and antagonist function (blue), drugs that target WNT receptor interactions (green), drugs that prevent dishevelled (DVL) activation (pink), drugs that stabilize the destruction complex (grey), and drugs that target $\beta$-catenin partners in the nucleus (purple). NPs, nanoparticles. 
Fig 5

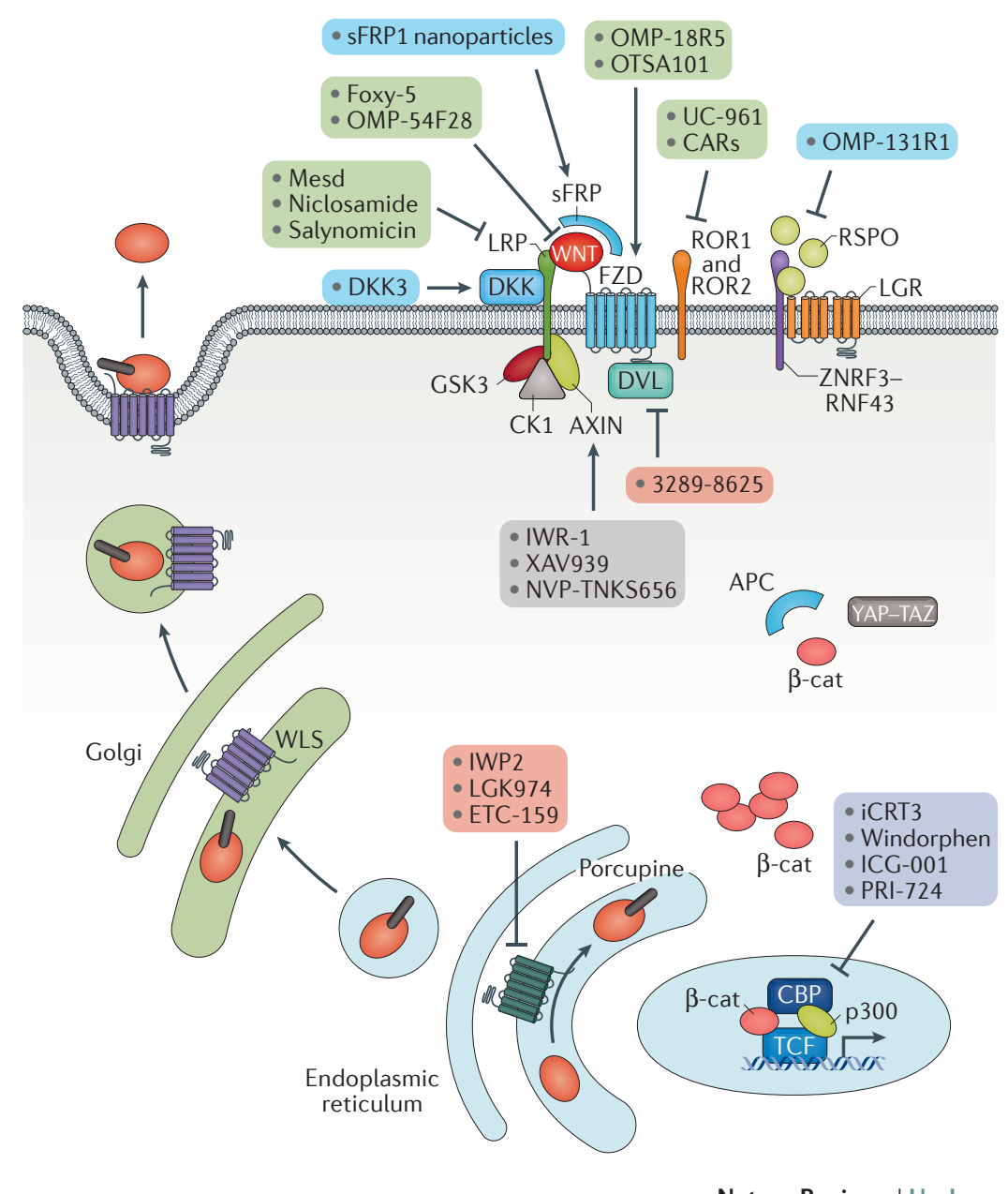

Nature Reviews | Urology 
Table 1 | Key changes in WNT signalling pathway components in prostate cancer

\begin{tabular}{|c|c|c|c|}
\hline $\begin{array}{l}\text { WNT } \\
\text { pathway } \\
\text { compon } \\
\text { ent }\end{array}$ & $\begin{array}{l}\text { Altera } \\
\text { tion }\end{array}$ & Disease stage & $\begin{array}{l}\text { Effect on WNT signalling, and/or on } \\
\text { prostate cancer cells, and on patients if } \\
\text { known }\end{array}$ \\
\hline $\begin{array}{l}\beta- \\
\text { catenin } \\
\text { (CTNNB } \\
1 \text { ) } \\
\end{array}$ & $\begin{array}{l}\text { Activat } \\
\text { ing } \\
\text { mutati } \\
\text { ons } \\
\end{array}$ & $\mathrm{CRPC}^{44,46}$ & Disease progression (mice) \\
\hline APC & $\begin{array}{l}\text { Inactiv } \\
\text { ating } \\
\text { mutati } \\
\text { ons } \\
\text { SNPs }\end{array}$ & $\begin{array}{l}\text { CRPC }^{45,46} \\
\text { Advanced prostate } \\
\text { cancer }^{48}\end{array}$ & $\begin{array}{l}\text { Disease progression (mice) } \\
\text { Decreased PSA-free survival }{ }^{47,48}\end{array}$ \\
\hline \multicolumn{4}{|l|}{ Ligands } \\
\hline WNT5A & $\begin{array}{l}\text { Upreg } \\
\text { ulation }\end{array}$ & $\begin{array}{l}\text { CTCs from CRPC } \\
\text { and } \mathrm{ADT}^{73} \text { patients }^{6} \\
\text { with tumours }^{66,74} \text { and } \\
\text { metastases } \\
\text { Localized cancer }\end{array}$ & $\begin{array}{l}\text { Noncanonical: increased CRPC growth, bone } \\
\text { metastasis; metastasis and recurrence }{ }^{61} \\
\text { Increased survival, improved outcome }\end{array}$ \\
\hline WNT7B & $\begin{array}{l}\text { Upreg } \\
\text { ulation }\end{array}$ & $\begin{array}{l}\text { Tumours }^{14} \\
\text { CTCs from patients } \\
\text { receiving } \mathrm{ADT}^{73}\end{array}$ & $\begin{array}{l}\text { Noncanonical; induces osteoblastic response } \\
\text { in bone }\end{array}$ \\
\hline WNT11 & $\begin{array}{l}\text { Upreg } \\
\text { ulation }\end{array}$ & $\mathrm{ADT}^{\prime \prime}$, metastases $^{\prime 8}$ & $\begin{array}{l}\text { Noncanonical; promotes invasion and } \\
\text { neuroendocrine-like differentiation }\end{array}$ \\
\hline WNT16B & $\begin{array}{l}\text { Upreg } \\
\text { ulation }\end{array}$ & Tumour stroma $^{101}$ & Canonical; therapy resistance ${ }^{101}$ \\
\hline \multicolumn{4}{|l|}{$\begin{array}{l}\text { Recepto } \\
\text { rs }\end{array}$} \\
\hline FZD2 & $\begin{array}{l}\text { Upreg } \\
\text { ulation }\end{array}$ & CRPC & Recurrence $^{/ 1}$ \\
\hline FZD4 & $\begin{array}{l}\text { Upreg } \\
\text { ulation }\end{array}$ & $\begin{array}{l}\text { ERG positive } \\
\text { tumours }\end{array}$ & Canonical and noncanonical; EMT ${ }^{110}$ \\
\hline FZD5 & $\begin{array}{l}\text { Upreg } \\
\text { ulation }\end{array}$ & Tumours $^{90}$ & Noncanonical \\
\hline FZD8 & $\begin{array}{l}\text { Upreg } \\
\text { ulation }\end{array}$ & Tumours $^{111}$ & Canonical and noncanonical \\
\hline ROR1 & $\begin{array}{l}\text { Upreg } \\
\text { ulation }\end{array}$ & Tumours $^{86}$ & Noncanonical; not known \\
\hline \multicolumn{4}{|l|}{$\begin{array}{l}\text { Regulat } \\
\text { ors }\end{array}$} \\
\hline SFRP1 & $\begin{array}{l}\text { Downr } \\
\text { egulati } \\
\text { on }\end{array}$ & Tumours ${ }^{8,89}$ & Reduced survival $^{88}$ \\
\hline SFRP2 & $\begin{array}{l}\text { Upreg } \\
\text { ulation }\end{array}$ & Tumour stroma $^{92}$ & $\begin{array}{l}\text { Potentiation of WNT-16B; therapy } \\
\text { resistance }^{92}\end{array}$ \\
\hline DKK1 & $\begin{array}{l}\text { Upreg } \\
\text { ulation }\end{array}$ & Serum $^{93}$, tumours ${ }^{64}$ & $\begin{array}{l}\text { Increased tumour growth, bone metastases }{ }^{94} \\
\text { and osteolytic lesions }{ }^{95} \text { in mice; poor } \\
\text { prognosis in patients }{ }^{93}\end{array}$ \\
\hline DKK3 & $\begin{array}{l}\text { Downr } \\
\text { egulati } \\
\text { on }\end{array}$ & Tumours & Inhibits tumour growth and metastasis ${ }^{123,124}$ \\
\hline
\end{tabular}




\begin{tabular}{|l|l|l|l|}
\hline $\begin{array}{l}\text { ZNRF3 } \\
\text { or } \\
\text { RNF43 }\end{array}$ & $\begin{array}{l}\text { Inactiv } \\
\text { ating } \\
\text { mutati } \\
\text { ons }\end{array}$ & CRPC $^{46}$ & Potentiation of WNT signals \\
\hline RSPO2 & $\begin{array}{l}\text { Upreg } \\
\text { ulation } \\
\text { (gene } \\
\text { fusion) }\end{array}$ & CRPC $^{46}$ & Potentiation of WNT signals \\
\hline
\end{tabular}

APC, adenomatous polyposis coli protein; CRPC, castration-resistant prostate cancer; DKK, Dickkopf-related protein; FZD, frizzled; ROR, tyrosine-protein kinase transmembrane receptor; RSPO, R-spondin; SFRP, secreted frizzled-related protein

\section{Table 2 | WNT pathway inhibitors in clinical trials}

\begin{tabular}{|c|c|c|c|c|}
\hline \begin{tabular}{|l|} 
Inhibitor \\
\end{tabular} & Target & Clinical trial & Phase & Ref \\
\hline \multicolumn{5}{|l|}{ Inhibition of Wnt secretion } \\
\hline LGK974 (also known as WNT974) & Porcupine & $\begin{array}{l}\text { NCT01351103 } \\
\text { NCT02278133 }\end{array}$ & $\begin{array}{l}1 \\
1 / I 1\end{array}$ & \begin{tabular}{|l}
12,14 \\
13 \\
\end{tabular} \\
\hline ETC-159 (also known as ETC-1922159) & Porcupine & NCT02521844 & 1 & 14,14 \\
\hline \multicolumn{5}{|l|}{ Regulation of antagonists and agonists } \\
\hline Adenovirus expressing DKK3 (also known as REIC) & not defined & NCT01931046 & $\mathrm{I} / \mathrm{II}$ & 15 \\
\hline OMP131R10 & RSPO3 & NCT02482441 & I & 16 \\
\hline \multicolumn{5}{|l|}{ Targeting WNT receptor interactions } \\
\hline FOXY-5 & WNT5A receptors & $\begin{array}{l}\text { NCT02020291 } \\
\text { NCT02655952 } \\
\end{array}$ & I & $\begin{array}{l}17 \\
18 \\
\end{array}$ \\
\hline OMP-54F28 (Ipafricept) & WNT family & \begin{tabular}{|l|} 
NCT01608867 \\
NCT02092363 \\
NCT02069145 \\
NCT02050178 \\
\end{tabular} & $\begin{array}{l}1 \\
1 \\
1 \\
1\end{array}$ & \begin{tabular}{|l|}
19,15 \\
20,16 \\
21 \\
22 \\
\end{tabular} \\
\hline OMP-18R5 (Vantictumab) & FZD1 $2,5,7,8$ & \begin{tabular}{|l|} 
NCT01345201 \\
NCT01957007 \\
NCT01973309 \\
NCT02005315 \\
\end{tabular} & $\begin{array}{l}1 \\
1 \\
1 \\
1\end{array}$ & $\begin{array}{l}23 \\
24 \\
25 \\
26 \\
\end{array}$ \\
\hline OTSA101 & FZD10 & NCT01469975 & I & 27,16 \\
\hline UC-961 (Cirmtuzumab) & ROR1 & $\begin{array}{l}\text { NCT02222688 } \\
\text { NCT02860676 } \\
\text { NCT03088878 } \\
\text { NCT02776917 }\end{array}$ & $\begin{array}{l}1 \\
1 \\
1 / 11 \\
1\end{array}$ & $\begin{array}{l}28 \\
29 \\
30 \\
31\end{array}$ \\
\hline \multicolumn{5}{|l|}{ Targeting nuclear $\beta$-catenin partners } \\
\hline PRI-724 & CBP & $\begin{array}{l}\text { NCT01302405 } \\
\text { NCT01764477 } \\
\text { NCT01606579 } \\
\end{array}$ & $\begin{array}{l}1 \\
1 \\
1 / I I\end{array}$ & \begin{tabular}{|l}
32,18 \\
33 \\
34 \\
\end{tabular} \\
\hline
\end{tabular}

CBP, CREB-binding protein; DKK, Dickkopf-related protein; FZD, frizzled; ROR, tyrosine protein kinase transmembrane receptor; RSPO, R-spondin; SFRP, secreted frizzled-related protein

Competing interests statement

The authors declare no competing interests.

Publisher's note 